\title{
Star-Graft Quarterpolymer-Based Polymersomes as Nanocarriers for Co-Delivery of Hydrophilic/Hydrophobic Chemotherapeutic Agents
}

\author{
Zacharoula Iatridi, ${ }^{\dagger}$ Athina Angelopoulou, ${ }^{\ddagger}$ Efstathia Voulgari, ${ }^{\ddagger}$ Konstantinos Avgoustakis, ${ }^{\ddagger}, \$$ \\ and Constantinos Tsitsilianis*, ${ }^{*}+$
}

${ }^{\dagger}$ Department of Chemical Engineering and ${ }^{\ddagger}$ Department of Pharmacy, Medical School, University of Patras, 26500 Patras, Greece

${ }^{\S}$ Biomedical Research Foundation of Academy of Athens (BRFAA), Athens 11527, Greece

\section{Supporting Information}

ABSTRACT: We report the fabrication of polymersomes, using as building blocks star-graft quarterpolymers, composed of hydrophobic polystyrene and $\mathrm{pH}$-sensitive poly(2-vinylpyridine)- $b$-poly(acrylic acid) (P2VP-b-PAA) arms, emanated from a common nodule, enriched by thermosensitive poly $(N$-isopropylacrylamide) grafts covalently bonded on the PAA block-arms. These multicompartmental polymersomes were evaluated as nanocarriers for the encapsulation and controlled codelivery of doxorubicin (hydrophilic) and paclitaxel (hydrophobic) chemotherapeutic agents. The polymersomes can load these drugs in different compartments and can efficiently be internalized in the human lung adenocarcinoma epithelial cells, delivering their cargo and inducing high cell apoptosis. The release kinetics of both anticancer agents was controlled differently by the environmental conditions $(\mathrm{pH}$ and

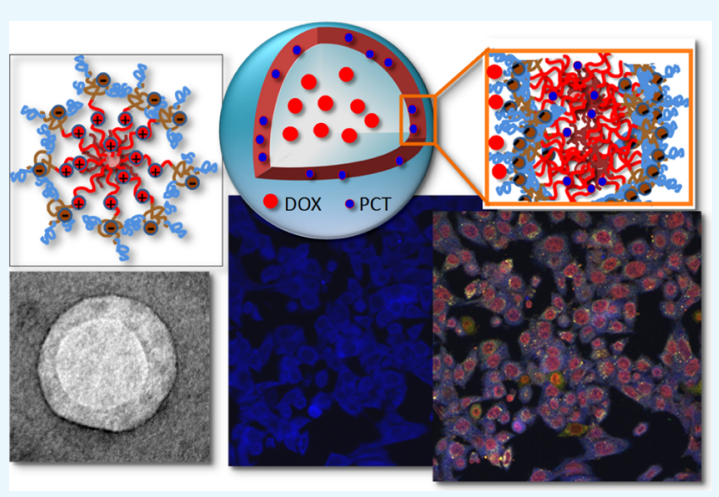
temperature). Enhanced release was observed at the acidic $\mathrm{pH} 6.0$ and under physiological temperature $\left(37^{\circ} \mathrm{C}\right)$. At the same total drug level, co-delivery of these drugs with the polymersomes caused enhanced cytotoxicity and induced significantly higher cell apoptosis in the cancer cell line compared to the polymersomes loaded with either of the two drugs.

\section{INTRODUCTION}

Star-shaped amphiphilic copolymers, exhibiting well-defined $3 \mathrm{D}$ architectures with various linear polymer arms emanating from a central core, constitute a unique class of macromolecular topology with exceptional functionality. ${ }^{1,2}$ One of the most interesting properties of these amphiphilic macromolecules is that they can adopt the morphology of polymeric micelles in aqueous media, namely unimolecular micelles, by internal segregation of their hydrophobic block/arms. The advantage of the unimolecular micelles versus polymolecular ones is that they never dissociate making them suitable nanocarriers of therapeutic agents under sink conditions. Moreover, stars with high number of arms and hence bearing high number of functional end-groups, enabling thus conjugations with targeting molecules, diagnostics, and drugs, exhibit additional potentials for biomedical applications. ${ }^{3-9}$

Water-soluble star-shaped terpolymers bearing three kinds of block/arms, some of which exhibiting responsive properties, have been designed previously, aiming to offer novel, more advanced potentials for uses as "smart" nanocarriers. ${ }^{10-13}$ Two are the main novel properties integrated to these star terpolymers, that is, compartmentalization of the star unimolecular nanostructure and responsiveness to $\mathrm{pH}$. The first one enables encapsulation of different molecules in the different compartments of the star terpolymer and the second one allows controlled delivery upon varying $\mathrm{pH}$.
Another strategy to take advantage of the compartmentalized responsive stars is to incorporate them, through layer-bylayer (LbL) techniques, into higher order assemblies, namely multicompartmental microcapsules, facilitating the ability for concurrent storage of hydrophobic and hydrophilic species in the hydrophobic compartments of the shells and in the aqueous lumen of the microcapsule respectively. ${ }^{14-18}$ Additionally, the hydrophilic weak polyelectrolyte segments of the star building blocks of the microcapsule allow the $\mathrm{pH}$ controlled loading and release of the different cargos by controlling the permeability of the microcapsule shell.

Among hollow nanocarrier systems used in co-delivery of multiple drugs, polymersomes composed of amphiphilic block copolymers and providing a bilayered membrane are favorable self-assembled polymeric systems, similar to lipids. ${ }^{19,20}$ Because of their structure, polymersomes are characterized as advantageous systems affording the simultaneous encapsulation of hydrophilic compounds in their aqueous cavities and hydrophobic compounds in their membranes, such as drugs, genes, proteins, and diagnostic probes. ${ }^{21-24}$ Furthermore, polymersomes facilitate selective tumor targeting by incorporating $\mathrm{pH}$ and/or thermosensitive segments in the building copolymer.

Received: June 25, 2018

Accepted: September 11, 2018

Published: September 25, 2018 

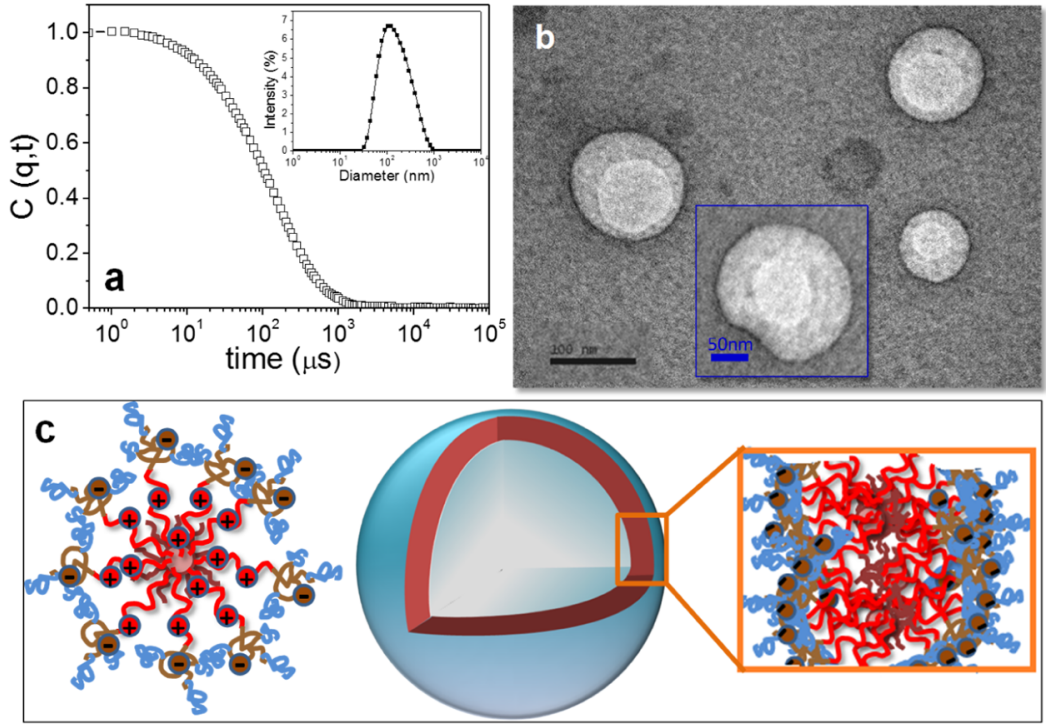

Figure 1. (a) Correlation function and intensity weighted hydrodynamic diameter of the SGQP polymersomes, (b) TEM micrographs of polymersomes formed by the SGQP (black scale bar $100 \mathrm{~nm}$, blue scale bar $50 \mathrm{~nm}$ ), and (c) schematic illustration of the involved star-graft polymers (left) and their segmental segregation in the wall of polymersomes, at physiological $\mathrm{pH}$ with the uncharged P2VP being hydrophobic (right). The different colors denote different arm segments: dark red PS, red P2VP, brown PAA, and blue PNIPAM grafts.

Stimuli-responsive polymersomes with $\mathrm{pH}^{25-32}$ or thermosensitive $^{33,34}$ polymer blocks have been extensively studied as delivery systems of hydrophobic or hydrophilic therapeutic and diagnostic agents. Specifically, the variations of $\mathrm{pH}$ or temperature of the surrounding environment lead to changes on the conformation and/or integrity of the polymersome permitting the site-selective release of the polymersomeentrapped bioactive agent. ${ }^{25-34} \mathrm{Li}$ et al., developed recently glucose oxidase (GOD)-loaded vesicular nanoreactors based on a diblock copolymer, which could be activated by tumor acidity to produce $\mathrm{H}_{2} \mathrm{O}_{2}$ increasing tumor oxidative stress. High levels of $\mathrm{H}_{2} \mathrm{O}_{2}$ also induced self-destruction of the vesicles releasing quinone methide to deplete glutathione and suppress the antioxidant ability of cancer cells. This synergistic effect of the nanoreactors resulted in tumor ablation. ${ }^{35}$ Also, GOD was efficiently loaded in polymersomes formed from diblock copolymers of poly(ethylene glycol) (PEG) and copolymer of camptothecin (CPT) and methacrylate modified with piperidine groups. In the environment of tumor tissues, the acidity of the tumor triggered the generation of $\mathrm{H}_{2} \mathrm{O}_{2}$, and as a consequence the release of CPT. The cancer cells were killed and the growth of tumor due to oxidation/chemotherapy was suppressed through the synergistic action of high oxidative stress of the tumor as well as the released drugs of CPT. ${ }^{36}$

In a previous work, our group reported the synthesis and characterization of novel star-graft quarterpolymers (SGQPs). These multiarmed and multiresponsive $\mathrm{PS}_{n}[\mathrm{P} 2 \mathrm{VP}-b$-(PAA- $g$ PNIPAM) $]_{n}$ macromolecules consisted of two types of arms, short hydrophobic polystyrene (PS) arm, and $\mathrm{pH}$-responsive hydrophilic poly(2-vinylpyridine)- $b$-poly(acrylic acid) (P2VP$b$-PAA) block copolymer arm with grafted poly $(N$-isopropylacrylamide) (PNIPAM) chains on the PAA outer block. ${ }^{37}$ The SGQP polymers exhibited stimuli-responsive behavior in aqueous media owing to the $\mathrm{pH}$-responsive weak P2VP and PAA polyelectrolyte segments as well the thermoresponsive PNIPAM grafting chains. Recently, PS $_{n}[\mathrm{P} 2 \mathrm{VP}-b-(\mathrm{PAA}-g-$ PNIPAM) $]_{n}$ was used for the development of polymeric microcapsules of a few micrometer size for the co-delivery of hydrophobic and hydrophilic molecules. ${ }^{38}$ In these microcapsules, the star-graft unimolecular micelles formed the multilayered shell, through the LbL technique, using tannic acid for H-bonding interconnection of the polymer layers. The compartmentalized layers served as the host area for incorporating the hydrophobic compound, while the hydrophilic macromolecules were encapsulated in the aqueous lumen of the microcapsules. The results obtained for the dualloaded microcapsules justified further investigation on the potential of the $\mathrm{PS}_{n}[\mathrm{P} 2 \mathrm{VP}-b-(\mathrm{PAA}-g \text {-PNIPAM })]_{n}$ polymer to be used in designing stimuli-sensitive delivery systems for the co-delivery of chemotherapeutics agents.

The aim of the present work was to evaluate the capability of these SGQPs to be integrated in stimuli-responsive vesicular assemblies (polymersomes) of nanometer size, in order to take advantage of the enhanced permeability and retention effect (EPR), which permits the accumulation of drug nanocarriers to inflammation and tumor sites following intravenous administration. ${ }^{39,40}$ This multisegmental SGQP bears various segments conferring specific functionalities to the formed polymersomes such as amphiphilicity (hydrophobic and hydrophilic compartments) along with $\mathrm{pH}$ /thermo-sensitivity. The polymersomes were explored for their capability of loading simultaneously two anticancer drugs, namely doxorubicin (DOX) and paclitaxel (PCT). Co-delivery of these two anticancer agents using advanced nanocarrier systems has been shown to achieve enhanced anticancer efficacy. ${ }^{41,42}$ The synergistic effect may result from the combination of individual antitumor mechanism of DOX and PCT. ${ }^{41}$ DOX binds to DNA by intercalation, inhibiting further DNA and RNA biosynthesis, whereas PCT stabilizes microtubules preventing cell division. Both DOX and PCT lead finally to cancer cell apoptosis. $^{21,41}$ The hydrophilic DOX and the hydrophobic PCT chemotherapeutic agents were efficiently incorporated in the aqueous lumen and the membrane hydrophobic pockets of the polymersomes, respectively. Drug release from these polymersomes was controlled by $\mathrm{pH}$ and temperature. Interestingly, the drug-loaded polymersomes were readily 
internalized by human lung adenocarcinoma epithelial cells, inducing a high degree of cell apoptosis.

\section{RESULTS}

The integration of the star-graft, polymeric species in polymersome assemblies was not obvious because of the complex topology of the building blocks. Hence, a number of methods used for polymersome and/or liposome preparation were attempted, namely, step dialysis, film hydration, phase transfer from immiscible solvent $\left(\mathrm{CHCl}_{3}\right)$ to $\mathrm{H}_{2} \mathrm{O}$, evaporation of immiscible solvent $\left(\mathrm{CHCl}_{3}\right)$ from $\mathrm{H}_{2} \mathrm{O}$ using vacuum pump (see Figure S2), and miscible solvent evaporation [tetrahydrofuran $(\mathrm{THF}) / \mathrm{H}_{2} \mathrm{O}$ ] (see Figure S3). The latter method yielded nearly well-defined polymersomes as observed by transmission electron microscopy (TEM) and was adopted accordingly.

Physicochemical Characterization of Polymersomes. The size of the polymersomes was evaluated by dynamic light scattering and TEM microscopy and the morphology by TEM (Figure 1). In Figure 1a, a characteristic autocorrelation function along with the intensity weighted distribution of the hydrodynamic diameter of the as-prepared polymersomes is demonstrated. A mean diameter was estimated at $122 \mathrm{~nm}$ (PDI 0.515). TEM verified the spherical or "ring-shaped" hollow morphology of the polymersomes, with no aggregates or clustered polymersomes being formed (Figures $1 \mathrm{~b}$ and S3). In the schematic representation of the SGQP PS $[$ P2VP- $b$ (PAA-g-PNIPAM) $]_{n}$ (left of Figure 1c), it can be seen that the SGQP has two kinds of arms: one is the PS arm, whereas the other is the P2VP-b-PAA block copolymer, where the PAA blocks are grafted with PNIPAM chains. In basic conditions, PAA is deprotonated and behaves as a negatively charged polyelectrolyte, while the P2VP segments become hydrophobic and tend to collapse close to the PS/poly(divinylbenzene) (PDVB) core of the star. Segregation of the various blocks of the SGQP occurs during polymersome formation with the hydrophobic PS/P2VP (basic conditions) and the hydrophilic PAA/PNIPAM (room temperature) blocks forming the membrane and the inner/outer hydrophilic layers (shell), respectively (right of Figure 1c).

Colloidal Stability of Polymersomes. The size of the polymersomes (Figure 2a) did not change appreciably upon storage at ambient temperature for a period of 30 days. However, the $\zeta$-potential exhibited some alteration with time suggesting possible charge surface rearrangements (Figure 3a). The size characteristics of the polymersomes during incubation in electrolyte $(\mathrm{NaCl})$ solutions did not change significantly, even in high electrolyte concentrations (Figure 2a). The observed slight decrease should be attributed to the shrinkage of the shell of the polymersomes because of the electrostatic screening of the repulsive interactions among the PAA segments. However, the influence of $\mathrm{pH}$ is more pronounced. As can be observed in Figure 2b, the diameter of polymersomes decreased about $21 \%$ from $\mathrm{pH} 7.4(94.81 \pm 4.88 \mathrm{~nm})$, to $\mathrm{pH} 6(73.59 \pm 0.76 \mathrm{~nm})$. This might be ascribed to the conformational shrinkage of the corona PAA chain segments due to lowering of their degree of ionization. This might also be corroborated by attractions between the PAA negatively charged segments and the positively P2VP segments that have been partially protonated at $\mathrm{pH}$ 6. The $\zeta$-potential of polymersomes initially increased (became less negative) and stabilized at low negative values (from $-7.10 \pm 0.66 \mathrm{mV}$ up to $-8.90 \pm 0.36)$ at higher $\mathrm{NaCl}$ concentrations (Figure 3a),
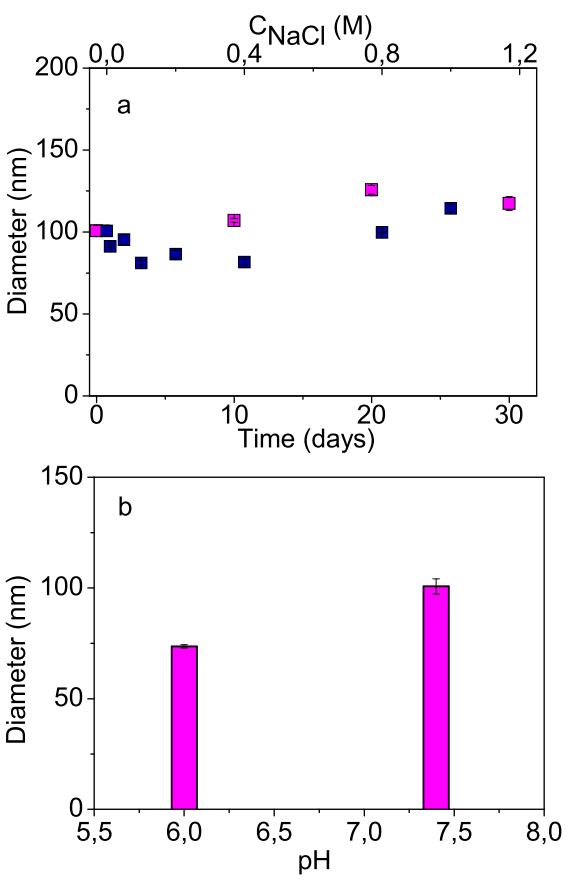

Figure 2. Size stability test of polymersomes at various conditions: (a) diameter vs time (magenta squares) and as a function of $\mathrm{NaCl}$ concentration (blue squares) and (b) in two different PB solutions ( $\mathrm{pH} 6$ and $\mathrm{pH} 7.4)$.
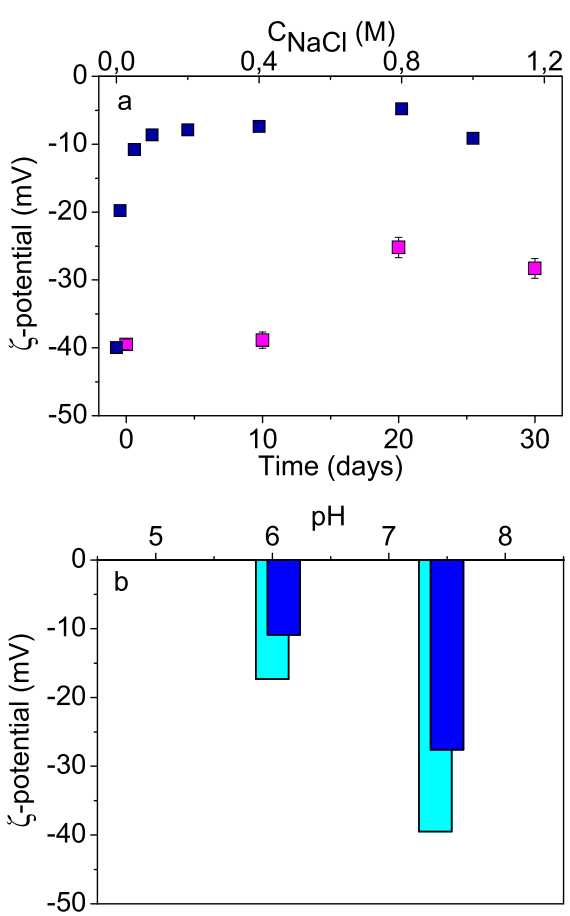

Figure 3. $\zeta$-Potential stability test of polymersomes at various conditions: (a) $\zeta$-potential vs time (magenta squares) and as a function of $\mathrm{NaCl}$ concentration (blue squares) and (b) $\zeta$-potential in two different $\mathrm{PB}$ solutions ( $\mathrm{pH} 6$ and $\mathrm{pH}$ 7.4). Darker blue bars correspond to the $\zeta$-potential of non-associated SGQP unimers.

which justifies the size reduction (Figure 2a). Evidence for a steric stabilization mechanism is provided because the polymersomes did not aggregate even at high electrolyte levels wherein their $\zeta$-potentials exhibit slightly negative values, probably due to repulsive interactions from the nonscreened, 
Table 1. Loading Characteristics of the DOX-Loaded, PCT-Loaded, and DOX/PCT-Loaded Polymersomes

\begin{tabular}{|c|c|c|c|c|c|c|}
\hline sample & & al loading (\%) & & capacity (\%) & \multicolumn{2}{|c|}{ entrapment efficiency (\%) } \\
\hline SGQP-DOX & & 9.92 & & $7 \pm 0.98$ & \multicolumn{2}{|c|}{$23.95 \pm 2.69$} \\
\hline SGQP-PCT & & 10 & & $8 \pm 1.26$ & \multicolumn{2}{|c|}{$57.28 \pm 3.48$} \\
\hline & \multicolumn{2}{|c|}{ theoretical loading (\%) } & \multicolumn{2}{|c|}{ loading capacity (\%) } & \multicolumn{2}{|c|}{ entrapment efficiency (\%) } \\
\hline sample & DOX & PCT & DOX & PCT & DOX & PCT \\
\hline SGQP-DOX/PCT & 9.08 & 9.1 & $3.89 \pm 0.59$ & $3.68 \pm 0.79$ & $36.5 \pm 0.48$ & $34.42 \pm 0.86$ \\
\hline
\end{tabular}

ionized AA moieties, preserved on the surface of the vesicle. The polymersomes after incubation at different $\mathrm{pH}$ for $24 \mathrm{~h}$ exhibited less negative values at $\mathrm{pH} 6(-17.30 \pm 0.82 \mathrm{mV})$ than $\mathrm{pH} 7.4(-39.50 \pm 3.29 \mathrm{mV})$ (Figure $3 \mathrm{~b})$. This effect should be attributed to the partially protonation of the deprotonated carboxylic groups (AA units), located on the surface of the polymersomes, upon lowering $\mathrm{pH}$. We mention here that the same effect was observed for the same reason for the star-graft unimers (Figure $3 \mathrm{~b}$ ). The higher $\zeta$-potential of the polymersome self-assemblies with respect to their unimers is reasonable because of the different surface area.

Loading Drugs to the Polymersomes. The drug loading characteristics of the polymersomes are presented in Table 1 . As can be seen, the polymersomes displayed DOX loading capacity $2.57 \%(\mathrm{w} / \mathrm{w})$ for a theoretical (feed) loading $9.92 \%$ $(\mathrm{w} / \mathrm{w})$ and PCT loading capacity $5.98 \%(\mathrm{w} / \mathrm{w})$ for a theoretical loading $10 \%(\mathrm{w} / \mathrm{w})$. The loading capacity of the dual DOX/PCT polymersomes was nearly $4 \%(\mathrm{w} / \mathrm{w})$ for both drugs for a theoretical loading of $9 \%(w / w)$. From TEM observation of the DOX- or PCT-loaded SGQP polymersomes, it was confirmed that the drug loading procedure (rotary vacuum evaporation, centrifugation, and redispersion in water) did not affect the formation of polymeric vesicles (Figure S4).

Indeed, both the DOX-loaded (Figure S4a,b) and PCTloaded (Figure S4c,d) SGQPs self-assembled in a vesicular nanostructure. The average size of the DOX-loaded and the PCT-loaded polymersomes was $133.9 \pm 13.7$ and $175.7 \pm 14.7$ $\mathrm{nm}$, respectively.

Drug Release Profiles from Polymersomes. In Figure 4, the release profiles of DOX and PCT are demonstrated for 0$6 \mathrm{~h}$ (Figure S5 also presents the data up to $48 \mathrm{~h}$ ). Sustained drug (DOX or PCT) release from the single- or dual-loaded polymersomes was observed, which was influenced by the $\mathrm{pH}$ and temperature experimental conditions. The results of DOX release in the first $3 \mathrm{~h}$, in both single- and dual-loaded polymersomes, show some burst effect. Because of ionic interactions between the positively charged DOX (amino group; $\mathrm{pK}, 8.6$ ) and the negatively charged $\mathrm{PAA},{ }^{43}$ a portion of DOX seems to be trapped in the outer shell of the polymersomes, which is delivered rapidly. The change of $\zeta$ potential between the blank polymersomes $(-39.50 \pm 3.29$ $\mathrm{mV})$ and the DOX-loaded ones $(-22.1 \pm 1.69 \mathrm{mV})$ is consistent with this assumption. At longer time (see also Figure S5), DOX was released faster at $\mathrm{pH} 6$ than at $\mathrm{pH} 7.4$, especially at $37^{\circ} \mathrm{C}$ (Figure 4a,c). At pH 7.4, DOX release was faster at $25^{\circ} \mathrm{C}$ than at $37^{\circ} \mathrm{C}$, especially with the single-loaded system, whereas at $\mathrm{pH} 6$ the temperature did not affect DOX release (Figure $4 a, c)$ ). PCT release from the single-loaded polymersomes was faster at $\mathrm{pH} 6$ than at $\mathrm{pH} 7.4$ at both temperatures and faster at $37{ }^{\circ} \mathrm{C}$ in both pHs (Figure $4 \mathrm{~b}$ ). PCT release was slower in the case of the dual-loaded polymersomes compared to the single-loaded ones (Figure $4 \mathrm{~b}, \mathrm{c})$. The $\mathrm{pH}$ affected significantly PCT release form the dual-
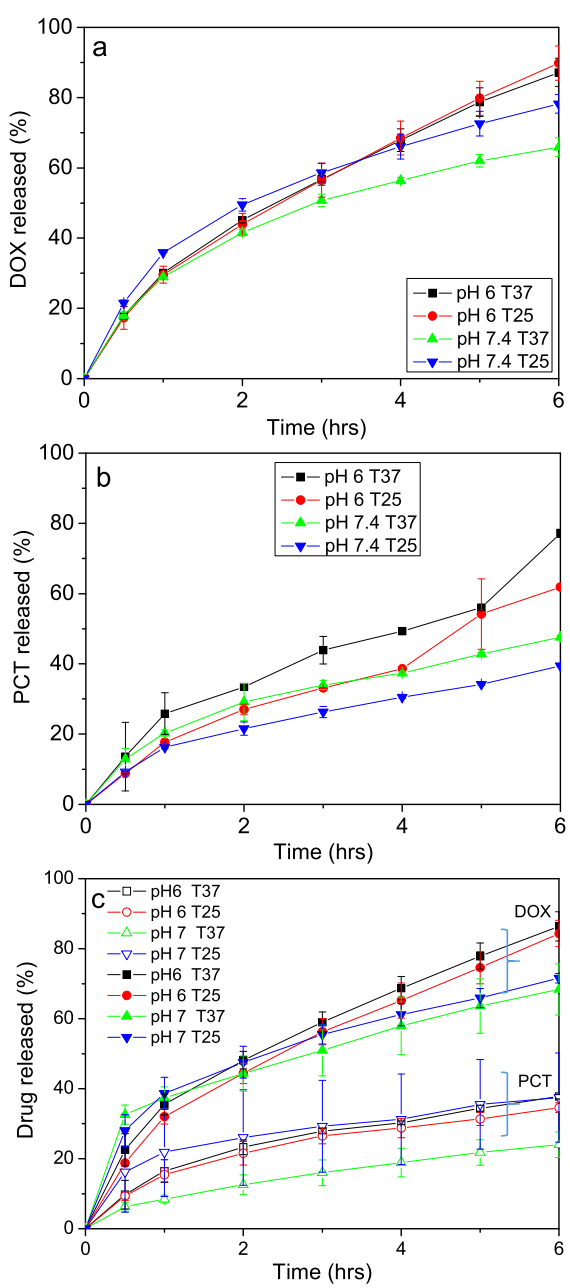

Figure 4. (a) Release profiles of DOX from the single-loaded polymersomes at $\mathrm{PB}$ of $\mathrm{pH} 7.4$ and 6 at 37 and $25{ }^{\circ} \mathrm{C}$, (b) release profiles of PCT from single-loaded polymersomes at $\mathrm{PB}$ of $\mathrm{pH} 7.4$ and 6 at 37 and $25^{\circ} \mathrm{C}$, and (c) co-release profiles of DOX (solid symbols) and PCT (open symbols) from dual-loaded polymersomes at PB of $\mathrm{pH} 7.4$ and 6 at 37 and $25{ }^{\circ} \mathrm{C}$.

loaded polymersomes only in the case of $37{ }^{\circ} \mathrm{C}$, with the $\mathrm{pH}$ 7.4 leading to much slower release compared to $\mathrm{pH} 6$ (Figure $4 b, c)$.

Cytotoxicity and Cellular Uptake. The viability of A549 cancer cells was assessed after 24 and $48 \mathrm{~h}$ of incubation with blank (without drug) and drug-loaded polymersomes. With the blank polymersomes, high cell viability values were obtained at all concentrations tested (almost $100 \%$ at $24 \mathrm{~h}$ and above $80 \%$ at $48 \mathrm{~h}$ ) (Figure S6). The drug-loaded polymersomes exhibited dose- and time-dependent cytotoxicity against the A549 cancer cells (Figure 5). The cytotoxicity of free DOX and DOXloaded polymersomes was increased with DOX concentration and incubation time (Figure 5). The DOX-loaded polymer- 

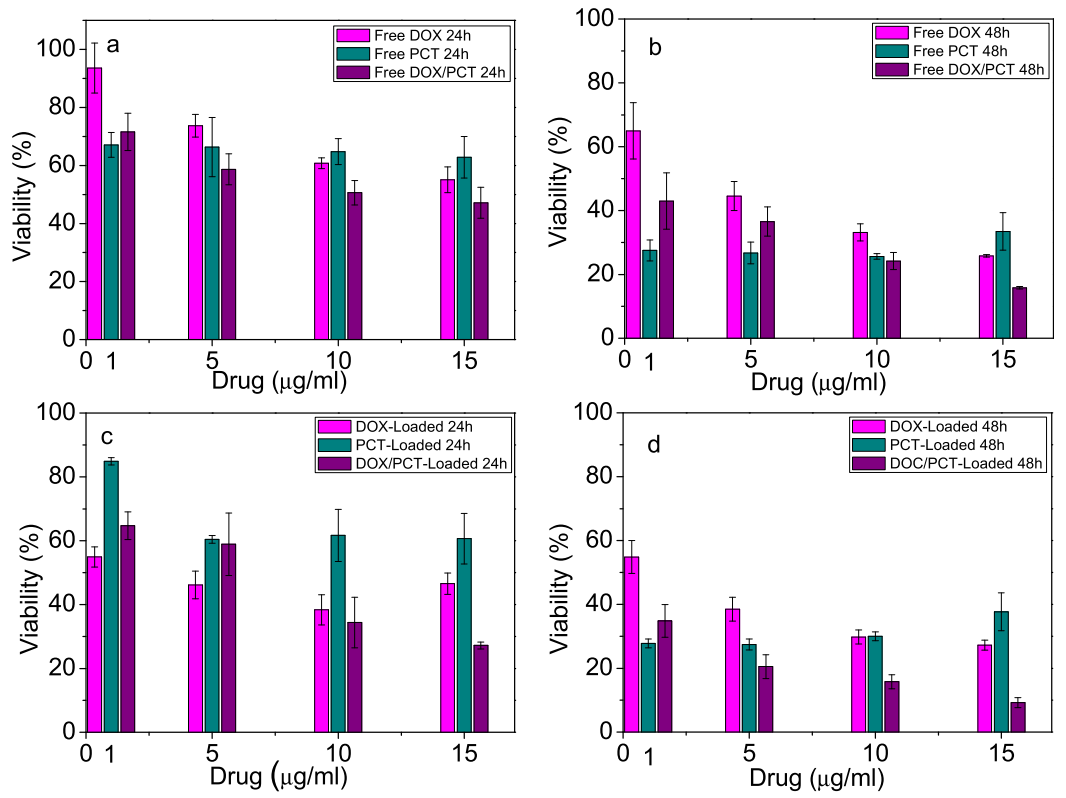

Figure 5. Viability of A549 cancer cells following incubation with different concentrations of free (a,b) and polymersome (c,d) entrapped drugs for $24(\mathrm{a}, \mathrm{c})$ and $48 \mathrm{~h}(\mathrm{~b}, \mathrm{~d})$.

somes exhibited higher cytotoxicity than free DOX in equivalent drug concentrations, the difference in cytotoxicity being more pronounced at $24 \mathrm{~h}$ (Figure 5, Table 3). In the case of PCT, the cytotoxicity of both the free and polymersome-entrapped drug was significantly increased with incubation time (Figure 5), but the effect of drug concentration was less pronounced than in the case of DOX for the range of concentrations tested here. At both incubation times, the free and polymersome-entrapped PCT exhibited comparable cytotoxicities at equivalent PCT levels (Figure 5, Table 3). At equivalent drug concentrations, the dual drugloaded polymersomes exhibited higher cytotoxicity than the mixture of the two drugs (free DOX plus free PCT) at both 24 and $48 \mathrm{~h}$ (Figure 5, Table 3 ). At relatively high concentrations, the dual drug-loaded polymersomes, that is, those carrying both DOX and PCT, exhibited enhanced cytotoxicity compared to the single drug-loaded polymersomes (Figure 5). The cytotoxicity differences between the dual drug-loaded polymersomes and the respective single drug-loaded polymersomes were statistically significant $(p<0.05)$ at drug concentrations higher than $5 \mu \mathrm{g} / \mathrm{mL}$ for the $24 \mathrm{~h}$ incubation and higher than $1 \mu \mathrm{g} / \mathrm{mL}$ for the $48 \mathrm{~h}$ incubation.

The induction of A549 cell apoptosis by the drug-loaded polymersomes was assessed at a total drug concentration of 5 $\mu \mathrm{g} / \mathrm{mL}$ (Figure 6). The dual drug-loaded polymersomes (DOX/PCT 1:1 by weight) induced apoptosis in more than double population (\%) of cells compared to the single drugloaded polymersomes at the same total drug concentration. The differences in the degree of apoptosis between the dualloaded polymersomes and the single-loaded polymersomes were highly significant $(p<0.01)$. As might have been expected from the lack of cytotoxicity (Figure S6), the blank polymersomes did not induce cell apoptosis (Figure 6). The concentration of the blank polymersomes in the apoptosis test was $80 \mu \mathrm{g} / \mathrm{mL}$, that is, equal to the carrier concentration used to generate the respective drug concentration of $5 \mu \mathrm{g} / \mathrm{mL}$ in the case of the drug-loaded polymersomes.

The uptake of DOX-loaded polymersomes which had been labeled with fluorescein isothiocyanate (FITC content $3.21 \pm$

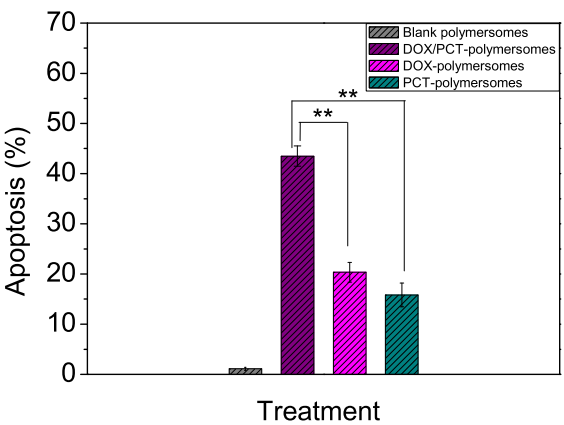

Figure 6. Apoptosis of A549 cells after $24 \mathrm{~h}$ of incubation with blank polymersomes, dual drug-loaded polymersomes (DOX/PCT 1:1 by weight), DOX-loaded polymersomes, and PCT-loaded polymersomes at a total drug concentration of $5 \mu \mathrm{g} / \mathrm{mL}$. The concentration of blank nanoparticles was $80 \mu \mathrm{g} / \mathrm{mL}$ and corresponded to the carrier concentration used to generate the drug concentration tested in the case of the drug-loaded polymersomes.

$0.36 \%$, DOX content $2.57 \pm 0.98 \%$ ) by the A549 cancer cells was evaluated at 1,4 , and $24 \mathrm{~h}$ by FACS (Figure $7 \mathrm{a}$ ). The uptake of polymersomes by the cancer cells was increased from $30 \%$ at $1 \mathrm{~h}$ to $40 \%$ at $24 \mathrm{~h}$. As the cell uptake of total DOX was measured at the different incubation times, that is, both the leaked from the carrier fraction of DOX and the (still) entrapped in the carrier fraction of DOX, cell uptake of DOX was faster than the carrier (FITC-labeled polymersomes) (Figure 7a). This effect suggests that part of DOX has been entrapped in the outer PAA layer of the polymersomes (ionic interactions), which is released before the nanocarriers enter into the cell. This is in consistent with the DOX release profiles in the first $3 \mathrm{~h}$. For the incubation times tested, an inverse linear correlation between DOX uptake and cell viability was observed (Figure $7 \mathrm{~b}$ ).

The uptake of the FITC-labeled, DOX-loaded polymersomes was visualized by confocal laser microscopy (Figure 8 ). At early times $(1 \mathrm{~h})$, red and green colors were mostly colocalized in the merged picture, indicating that the main fraction of DOX (red) still remained within the polymersomes 

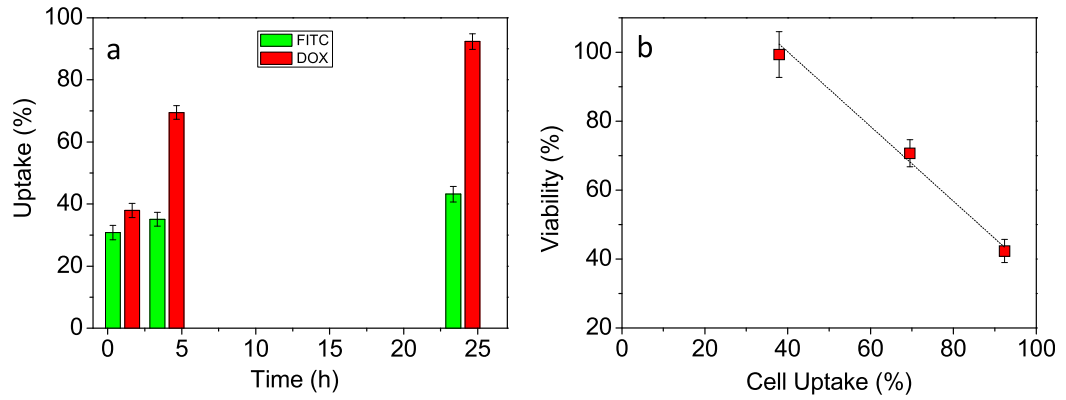

Figure 7. Cellular uptake of DOX (DOX) and DOX-loaded polymersomes labeled with FITC (FITC) by A549 cells after 1, 4, and 24 h of incubation (a) and relation of A549 cells viability with the uptake of the DOX-loaded polymersomes by these cells (b).
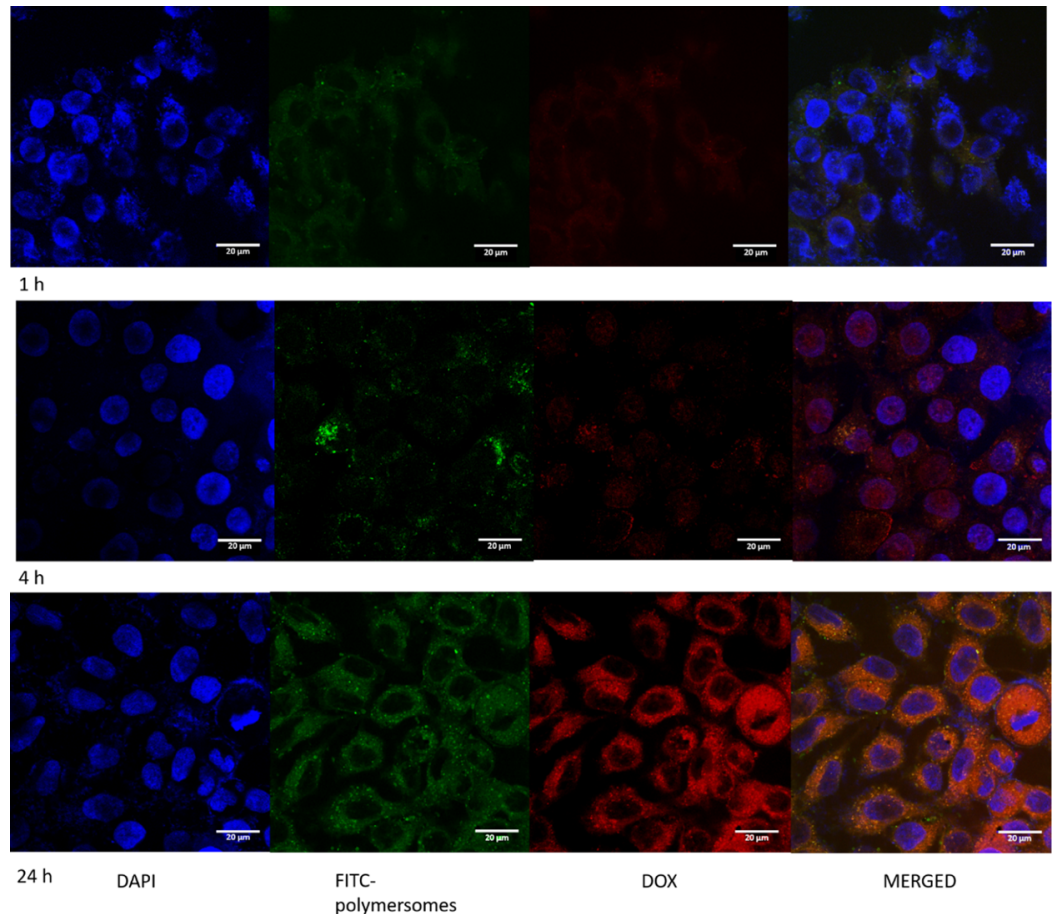

Figure 8. Confocal fluorescence microscopy images of the uptake of FITC-labeled DOX-polymersomes by the A549 cancer cells at 1, 4, and 24 h. From left to right, the panels in each row show fluorescence from DAPI (nuclei stained blue), FITC-polymersomes (polymersomes stained green), DOX (red fluorescence of the drug), and merged images. In merged pictures, co-localization of FITC and DAPI gives yellow-green color, colocalization of DOX and DAPI gives red-purple color, and co-localization of FITC, DOX, and DAPI gives orange color. The scale bars are $20 \mu \mathrm{m}$.

(green), which were localized in the area around the nuclei of the cells. At longer incubation times (4 and $24 \mathrm{~h}$ ), the polymersomes were surrounding the nuclei of the cells. At $4 \mathrm{~h}$, a portion of DOX (liberated from the polymersomes) was surrounding cell nuclei or was within the nuclei. At $24 \mathrm{~h}$ a higher amount of DOX can be seen intracellularly compared to $4 \mathrm{~h}$, with the DOX located mainly around cell nuclei and only a small part of it being within cell nuclei (Figure 8). For clarity, the confocal images of FITC label and DOX are also given separately in Supporting Information (Figures S7 and S8).

\section{DISCUSSION}

Lately, the combination therapy has been recognized as an efficient strategy in cancer treatment, as more than one drug is applied with different action sites. Among the advantages of combination therapy, the most important is the diminution of side effects of drugs because decreased doses are required, and in most cases, a synergistic therapeutic effect is achieved, which has resulted in suspending cancer cell mutations and cancer adjustment process. ${ }^{41,44-47}$ However, an optimum synergistic anticancer activity is difficult to be achieved as the therapeutic result of a combination of two or more free drugs is highly affected by the varied biochemical activities and pharmacokinetic behavior of drugs. ${ }^{42,48}$ Thus, the simple combination of free drugs commonly resulted in severe toxic adverse effects in cancer patients making their clinical application problematic. ${ }^{49}$ To address this problem, advanced nanomedicine can be utilized for the co-administration of different drugs into tumor cells with a delivery system, such as nanoparticles, micelles, and polymersomes. $^{41,45-47}$

Polymersomes exhibit larger mechanical stability and lower permeability than their structural lipid analogues, the liposomes. Their more robust, less leaky, and tunable membrane is very useful for improved stability in circulation. ${ }^{24}$ In this work, $\mathrm{pH}$ - and temperature-sensitive polymersomes of the SGQP PS $n$ [P2VP-b-(PAA- $g$-PNIPAM $)]_{n}$ for the co-delivery of DOX and PCT were prepared and characterized. The aim is to evaluate these (multi)stimuli-responsive polymersomes as nanocarriers to co-deliver two anticancer agents of different 
pharmacological activity mechanisms with a predefined releasing profile. These polymersomes can simultaneously encapsulate hydrophilic and hydrophobic compounds at different compartments and release their drug selectively under the effect of varied $\mathrm{pH}$ and temperature conditions. Codelivery of PCT and DOX has been also investigated using PLA-PEG nanoparticles ${ }^{41}$ and a PEG-polypeptide nanovehicle, $^{42}$ and the co-delivery nanosystems have been found to exhibit higher antitumor efficiency in reducing tumor size compared to free drug combination or single drug-loaded nanoparticles.

The SGQP polymersomes were prepared by the organic solvent evaporation method. ${ }^{50}$ This method provided polymeric vesicles of average sizes of $120 \mathrm{~nm}$ (depending on the environment) with a bilayered membrane and the ability to dual-encapsulate hydrophilic DOX in their aqueous lumens and hydrophobic PCT in their membranes (Scheme 1). The

Scheme 1. Schematic Representation of the DOX/PCT Dual-Loaded Polymersome and the Different Migration Pathways of the Hydrophobic/Hydrophilic Drug Transmembrane Diffusion

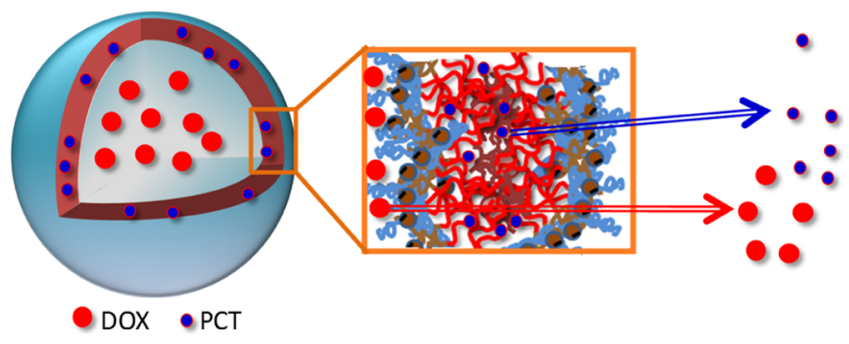

relative small size of the polymersomes (Figure 1) and their hydrophilic coating may represent suitable requirements for their accumulation in the tumor area following intravenous administration. Tumor accumulation of long-circulating nanocarriers is based on the EPR effect (passive targeting). 99,40

Colloidal stability, that is, the avoidance of aggregation on storage or in the physiological environment, is a prerequisite for nanocarriers intended for drug delivery applications. The SGQP polymersomes synthesized here showed an exceptional colloidal stability during storage and, in the presence of high concentration of electrolyte (Figures 2 and 3), much higher than the physiological one of $0.15 \mathrm{M}$.

The release of DOX or PCT from the single-loaded polymersomes exhibited different kinetics owing to their different hydrophilicity and in turn to their encapsulation in different compartments of the polymersomes. More importantly, their release profiles depend on environmental conditions such as $\mathrm{pH}(6$ or 7.4$)$ and temperature (25 or 37 ${ }^{\circ} \mathrm{C}$ ) (Figure $\left.4 \mathrm{a}, \mathrm{b}\right)$. Concerning $\mathrm{pH}$, both drugs display enhanced release at lower $\mathrm{pH}$ 6.0, which could be attributed mainly to the $\mathrm{pH}$-sensitive $\mathrm{P} 2 \mathrm{VP}$ segments, incorporated in the hydrophobic membrane. The ionic interactions between the positively charged DOX and the negatively charges of PAA segments do not change between 7.4 and $6,{ }^{43}$ and thus, they are not taken into consideration as far as the $\mathrm{pH}$ effect on the DOX release behavior is concerned. ${ }^{51}$ Thus, slight protonation (ionization) of the 2VP moieties at the lower pH 6 likely induces partial swelling of the membrane, increasing thus its permeability. ${ }^{30,31}$ The effect of temperature on release kinetics appears more complicated for the different drugs and depends on $\mathrm{pH}$. DOX release at $\mathrm{pH} 7.4$ slowed down upon heating to $37{ }^{\circ} \mathrm{C}$ (Figure 4a). At this temperature, PNIPAM segments turn into hydrophobic. However, because of the charged PAA arms, on where they are grafted, they do not exhibit intermolecular association. ${ }^{37,38}$ At $37^{\circ} \mathrm{C}$, therefore, DOX seems to meet another obstacle to overcome during its diffusion out of the wall. This is probably due to the creation of hydrophobic domains in the inner and outer hydrophilic layers of the polymersome walls. On the other hand, no appreciable temperature effect was observed at $\mathrm{pH}$ 6, which might be attributed to the fact that the determining factor for delivery of DOX (which is more hydrophilic in this $\mathrm{pH}$ ) is the permeability of the hydrophobic P2VP membrane, which is mainly affected by $\mathrm{pH}$. The hydrophobic PCT follows different migration pathways (Figure 4b). It is already located within the hydrophobic membrane and upon heating its delivery seems to be facilitated by the creation of the PNIPAM hydrophobic domains. Thus, the PCT release was enhanced upon heating and this appears independent of the $\mathrm{pH}$ of the release medium (Figure $4 \mathrm{~b}$ ). This result is in very good agreement with the heating-induced fast release of a hydrophobic probe (Nile red) from microcapsules fabricated by the same SGQP building blocks. $^{38}$

In the dual DOX/PCT-loaded polymersomes, the release of the hydrophilic DOX follows profiles similar to those of singleloaded polymersomes (Figure 4c). On the other hand, PCT release was restrained when released from the DOX/PCTpolymersomes, suggesting possible antagonistic effects between the two different drugs (Figure 4c). ${ }^{21,42,52}$ As we have mentioned above, it may also be possible that DOX, interacting via ionic interactions with the hydrophilic PAA blocks of the polymersome shell, will pose an additional obstacle in the diffusion of hydrophobic PCT through the membrane. The release rate of both drugs from the dualloaded polymersomes was much higher at $\mathrm{pH} 6$ than in $\mathrm{pH} 7.4$ under physiological temperature $\left(37^{\circ} \mathrm{C}\right.$ ) (Figure $4 \mathrm{c}$ ), and this is encouraging because it indicates that the dual system would not lose a significant fraction of its drug load in the blood, that is, before it reaches the tumor site where the $\mathrm{pH}$ is lower than the physiologic one, and even more so before being internalized within the acidic compartments (lysosomes) of the cancer cells in the tumor. That is, the system would exhibit a degree of selectivity of drug release in the site of drug action. $^{53,54}$

The blank polymersomes did not affect the viability (Figure S6) and did not induce apoptosis of A549 cancer cells (Figure 6), which is suggestive of the cytocompatibility of the nanocarrier, under the experimental conditions applied and the polymer concentrations used. At the same total drug level, the dual-loaded polymersomes (i.e., those carrying DOX and PCT) exhibited higher cytotoxicity against the A549 cancer cells compared to the single-loaded polymersomes (i.e., those carrying only DOX or only PCT) (Figure 5, Table 3) and induced a significantly higher degree of cell apoptosis (Figure 6), suggesting an enhanced anticancer effect due to the codelivery of the two drugs. ${ }^{21,42,52,55,56}$ DOX and PCT have been found to induce apoptosis in A549 cell line, ${ }^{57,58}$ and our results show that the polymersome-entrapped DOX and/or PCT can also induce A549 cells apoptosis (Figure 6). The combination index values for $50 \%$ cells survival $\mathrm{CI}_{50}$, estimated based on the cells viability data presented in Figure 5, suggest that codelivery to cells of DOX and PCT, either as free drugs or polymersome-entrapped, does not result to synergistic effect 
Table 2. Molecular Characteristics of the Heteroarm SGQP

\begin{tabular}{|c|c|c|c|c|}
\hline polymer $^{a}$ & $\begin{array}{c}M_{\mathrm{w}} \text { of star precursor }{ }^{b} \\
\left(\mathrm{~g} \mathrm{~mol}^{-1}\right)\end{array}$ & $\begin{array}{l}M_{\mathrm{w}} \text { of } \mathrm{SGQP}^{c} \\
\quad\left(\mathrm{~g} \mathrm{~mol}^{-1}\right)\end{array}$ & $\begin{array}{l}\text { average PNIPAM chains per PAA } \\
\text { arm }^{d}\end{array}$ & $\begin{array}{l}\text { PNIPAM weight } \\
\text { fraction }\end{array}$ \\
\hline SGQP:S33 ${ }_{9}\left(\mathrm{~V} 126-b-\mathrm{A} 69-g-\mathrm{N} 48_{4.5}\right)_{9}$ & 199000 & 426194 & 4.48 & 0.53 \\
\hline
\end{tabular}

${ }^{a_{T}}$ The numbers next to the letters denote the degree of polymerization of each block. The subscripts symbolize the number of arms and/or the grafted chains per arm. ${ }^{b}$ Calculated by light scattering of the heteroarm $\mathrm{PS}_{9}(\mathrm{P} 2 \mathrm{VP}-b-\mathrm{P} t \mathrm{BA}){ }_{9}$ precursor and assuming quantitative deprotection of tBA monomer units. ${ }^{c}$ Calculated from the $M_{\mathrm{w}}$ of the $\mathrm{PS}_{9}(\mathrm{P} 2 \mathrm{VP}-b-\mathrm{PAA})_{9}$ and the PNIPAM weight fraction. ${ }^{d}$ Calculated by ${ }^{1} \mathrm{H}$ NMR.

between the two drugs (Table 3). Hahn et al. also observed that exposure of A549 cells to DOX and PCT produced a lessthan-additive effect and related it with the effects of these drugs on cells cycle. ${ }^{59}$ It becomes apparent that the time and dose schedule of DOX/PCT co-delivery has to be optimized in order to obtain synergistic anticancer activity.

Cell uptake experiments showed that the SGQP polymersomes were capable of entering the A549 cancer cells (Figures 7 and 8). The cytotoxicity of the drug-loaded polymersomes, either single- or dual-loaded, increased with incubation time (Figure 5), probably because of the increasing internalization within the cells of the drug with time, as the cell uptake experiment with the DOX-loaded polymersomes shows (Figure 7). The confocal studies (Figures 8, S7 and S8) indicated that the polymersomes accumulated with time around cell nuclei and that their drug load (DOX) was liberated from the carrier with time, accumulating in the nuclei of the cells where it exerts its pharmacological activity.

Lack of the biodegradability of the nanocarrier is a drawback. For instance, we could replace PAA arms with the corresponding poly(aspartic acid) which is a biodegradable polypeptide. Thus, retro-design of the polymer building blocks is suggested before investigating the system further toward potential dual-anticancer drug delivery applications.

\section{CONCLUSIONS}

In this work, $\mathrm{pH} /$ thermosensitive amphiphilic $\mathrm{PS}_{9}(\mathrm{P} 2 \mathrm{VP}-b$ PAA-g-PNIPAM $)_{9}$ SGQPs were used as building blocks to form hollow vesicles (polymersomes) attempting various preparation methods. To the best of our knowledge, we show for the first time that such topologically complex multisegmented SGQPs can be integrated to polymersomes, bearing complex $\mathrm{pH}$-sensitive (P2VP block arms) hydrophobic membrane and thermosensitive (PNIPAM grafts) hydrophilic inner and outer corona.

The as-prepared polymersomes were evaluated as nanocarriers to carry anticancer model drugs (DOX and PCT) to human lung adenocarcinoma epithelial cells (A549). The polymersomes exhibited satisfactory single and dual drug loading efficiency and excellent colloidal stability. Drug release showed $\mathrm{pH}$ and temperature dependencies manifested differently for the hydrophobic and hydrophilic drugs, carried at different compartments. For the single-loaded and dual-loaded polymersomes, enhanced release was observed at low $\mathrm{pH} 6$ and at physiological temperature $\left(37^{\circ} \mathrm{C}\right)$.

In the dual DOX/PCT-loaded polymersomes, although the release of the hydrophilic DOX follows profiles similar to those of single-loaded polymersomes, the PCT release was restrained. However, at the same total drug level, the dual-loaded polymersomes exhibited higher cytotoxicity and induced significant higher degree of cell apoptosis (about 125\% enhancement in $24 \mathrm{~h}$ ) in the A549 cancer cell line compared to the single-loaded polymersomes.
The obtained results indicate the potential of the SGQP polymersomes to be simultaneously loaded with two anticancer drugs (hydrophobic/hydrophilic carried at different compartments) and release them slowly and in a $\mathrm{pH}$ dependent fashion in cancer cells, provoking a high degree of cell apoptosis.

\section{EXPERIMENTAL SECTION}

Materials. $N$-Ethyl- $N^{\prime}$-(3-dimethyl aminopropyl)carbodiimide hydrochloride (EDC $\cdot \mathrm{HCl},>98 \%, M_{\mathrm{w}}: 191.7 \mathrm{~g} /$ mol) and FITC (>90\% HPLC) were obtained from SigmaAldrich. PCT was purchased from LC Laboratories, USA. DOX hydrochloride (DOX $\cdot \mathrm{HCl}$ ) was purchased from Pfizer. All other chemicals and solvents were of analytical grade. Ultrapure 3D-water was obtained by means of an ELGA MEDICA apparatus.

Polymer Synthesis. The synthesis of the SGQP polymer $\left[\mathrm{PS}_{9}(\mathrm{P} 2 \mathrm{VP}-b \text {-PAA- } g \text {-PNIPAM })_{9}\right]$ with nine heteroarms has been described in a previous work. ${ }^{37}$ Briefly, the star terpolymer precursor, $\mathrm{PS}_{9}(\mathrm{P} 2 \mathrm{VP}-b-\mathrm{P} t \mathrm{BA})_{9}$, was synthesized through a one-pot/four-step sequential "living" anionic polymerization method. ${ }^{12,13,60}$ Initially, the PS arms were synthesized in THF using sec-BuLi as the initiator and the "living" PS chains were used to polymerize a small quantity of DVB. Polymerization of 2-vinyl pyridine (2VP) was initiated from the active sites in the PDVB core of the "living" star precursors $\left(\mathrm{PS}_{9}\right)$ leading to a $\mathrm{PS}_{9} \mathrm{P}_{2} \mathrm{VP}_{9}$ star polymer. Finally, tert-butyl acrylate $(t \mathrm{BA})$ was polymerized at the end sites of the P2VP arms. The $\mathrm{PS}_{9}(\mathrm{P} 2 \mathrm{VP}-b-\mathrm{PAA})_{9}$ terpolymer was obtained after acidic hydrolysis of the PtBA blocks in 1,4-dioxane with a 6 -fold excess of $\mathrm{HCl}$ at $80{ }^{\circ} \mathrm{C}$. The synthesis of the $\mathrm{PS}_{9}(\mathrm{P} 2 \mathrm{VP}-$ $b$-PAA-g-PNIPAM $)_{9}$ SGQP was performed according to the following steps. First, the $\mathrm{PS}_{9}(\mathrm{P} 2 \mathrm{VP}-b \text {-PAA })_{9}$ star terpolymer was dissolved in dimethylformamide (DMF), and aqueous $\mathrm{HCl}$ solution $(0.01 \mathrm{M})$ was added until a $3 / 7$ volume ratio of $\mathrm{DMF} / \mathrm{H}_{2} \mathrm{O}$. The solution was dialyzed against $\mathrm{HCl}$ solution $(0.01 \mathrm{M})$ to remove DMF [dialysis membrane; molecular weight cutoff (MWCO): $12000 \mathrm{Da}$. Further dialysis of the resulting solution with a $\mathrm{pH} 2$ was followed using aqueous solutions of $\mathrm{pH}$ 8. At the next stage, the grafting of amineterminated PNIPAM chains onto the neutralized PAA of the star terpolymer was achieved through carbodiimide chemistry, using EDC as a condensing agent. Nongrafted PNIPAM chains and excess of EDC were removed by dialysis against $\mathrm{H}_{2} \mathrm{O}$ (dialysis membrane; MWCO: $25000 \mathrm{Da}$ ). Finally, the SGQP was recovered by freeze drying. Detailed characterization of the polymer is reported elsewhere, ${ }^{37}$ and the basic molecular characteristics of the SGQP are presented in Table 2.

Synthesis and Characterization of Polymersomes. Polymersomes were prepared by the organic solvent evaporation method. ${ }^{50}$ In brief, predetermined amounts of the heteroarm SGQP polymer $(9 \mathrm{mg}$ ) were added in $0.5 \mathrm{~mL}$ of THF and stirred for $24 \mathrm{~h}$. Then, the mixture was added dropwise in $5.5 \mathrm{~mL}$ of ultrapure water under gentle agitation. 
Next, the organic solvent was evaporated in a rotary vacuum evaporator $\left(35^{\circ} \mathrm{C}\right)$ for $2 \mathrm{~h}$, wherein the polymersomes were hardened. Then, mild centrifugation at $3000 \mathrm{rpm}$ for $5 \mathrm{~min}$ was followed in order for the aggregates to be precipitated and the supernatant was collected. The purified polymersomes were stored at room temperature until further use. The yield was determined by freeze-drying of purified polymersomes and weighing the solid residues obtained.

The morphology of polymersomes was characterized by TEM using a JEOL JEM-2100 microscope at an acceleration potential of $200 \mathrm{kV}$, equipped with a GATAN camera Erlanashen ES500W, model 782. For TEM specimens, an aqueous polymersomes sample of $0.16 \mathrm{mg} / \mathrm{mL}$ was spread onto a carbon-coated cooper MS200 grid and air-dried before observation. A ZetaSizer Nano series Nano-ZS (Malvern Instruments Ltd, Malvern, UK) equipped with a $\mathrm{He}-\mathrm{Ne}$ Laser beam at a wavelength of $633 \mathrm{~nm}$ and a fixed backscattering angle of $173^{\circ}$ was used for the study of hydrodynamic diameter and $\zeta$-potential of the polymersomes in water.

The colloidal stability of the polymersomes was assessed by recording the average size and $\zeta$-potential with time (for 30 days) and the resistance of the polymersomes to aggregation induced by increasing concentrations of electrolyte $(\mathrm{NaCl})$ and by phosphate buffer (PB) solutions of $\mathrm{pH} 6$ and 7.4.

Synthesis and Characterization of FITC-Labeled Polymersomes. In order to prepare FITC-polymersomes, the SGQP polymer was labeled with the fluorescent dye FITC prior polymersomes preparation. The conjugation of FITC on the polymer was implemented between the carboxyl groups of the PAA arms and the amine moieties of FITC in the presence of EDC as the coupling agent. Particularly, $5 \mathrm{mg}$ of the polymer $\left(1.17 \times 10^{-8}\right.$ mol SGQP $)$ was dissolved in $4 \mathrm{~mL}$ of ultrapure water, and $1.5 \mathrm{mg}$ of EDC predissolved in $0.2 \mathrm{~mL}$ of cold ultrapure water $\left(4^{\circ} \mathrm{C}\right)$ was added dropwise. The mixture was sonicated in an ice bath for $1 \mathrm{~h}$, and the $\mathrm{pH}$ was adjusted to 8.0 with $\mathrm{Et} 3 \mathrm{~N}$ ( $100 \mu \mathrm{L}$ of $0.35 \%$ solution). Then, FITC 0.1 $\mathrm{mg}\left(2.6 \times 10^{-7} \mathrm{~mol}\right.$ FITC $)$ from a stock solution $(1 \mathrm{mg} / \mathrm{mL}$ in ultrapure water) was added dropwise in the dark, and the reaction solution was left under stirring at ambient temperature for $24 \mathrm{~h}$ in shade. The final ratio of FITC/SGQP was 22 (in moles). The product was purified by extended dialysis against $3 \mathrm{D}-\mathrm{H}_{2} \mathrm{O}$. The purified FITC-SGQP polymer was freeze-dried, in order to obtain the final product, and stored in a desiccator until further use. The amount of FITC label on SGQP was evaluated spectrophotometrically (excitation $480 \mathrm{~nm}$, emission $520 \mathrm{~nm}$ ) using a Shimadzu UV-1800 UV spectrophotometer. For the measurement, a standard curve within a range of FITC concentrations $5-50 \mu \mathrm{g} / \mathrm{mL}\left(R^{2}=0.983\right)$ was constructed and a modification rate of $3.01 \pm 0.89 \% \mathrm{w} / \mathrm{w}$ was achieved.

For the FITC-polymersomes, the FITC-SGQP polymer was used and the process was followed as described above (in section Synthesis and Characterization of Polymersomes).

Loading of Polymersomes with DOX and PCT. For DOX-loaded polymersomes, the above method was used. The hydrophilic DOX $(1 \mathrm{mg})$ was added in the aqueous phase of $5.5 \mathrm{~mL}$ ultrapure water and gently agitated in the dark for 30 min to completely homogenize. Then, the mixture of the polymer $(9 \mathrm{mg})$ in THF $(0.5 \mathrm{~mL})$ was added dropwise in the dark and left under gentle agitation for $30 \mathrm{~min}$. The ratio of DOX/SGQP was $1 / 9$ (in $\mathrm{mg}$ ). The dispersion was rotary vacuum-evaporated $\left(35^{\circ} \mathrm{C}\right)$ for $2 \mathrm{~h}$. In order to remove free (not encapsulated) DOX, the dispersion was centrifuged at 15 $000 \mathrm{rpm}$ for $1 \mathrm{~h}$ at $8{ }^{\circ} \mathrm{C}$, the precipitate with the DOX-loaded polymersomes was resuspended in the initial water volume, and the supernatant with the free DOX was discarded. The purified DOX-loaded polymersomes were stored in a fridge (4 ${ }^{\circ} \mathrm{C}$ ).

In order to prepare PCT-loaded polymersomes, the SGQP $(9 \mathrm{mg})$ was dissolved in THF $(0.5 \mathrm{~mL})$ and to this mixture PCT $(1 \mathrm{mg})$ dissolved in $0.1 \mathrm{~mL}$ of ethanol was added to an analogy of PCT/SGQP 1/9 (in $\mathrm{mg}$ ). The mixture was stirred for $24 \mathrm{~h}$ in the dark and then added dropwise in $5.5 \mathrm{~mL}$ of ultrapure water under gentle agitation. The dispersion was rotary vacuum-evaporated $\left(35^{\circ} \mathrm{C}\right)$ for $2 \mathrm{~h}$ to remove organic solvents (THF and ethanol). Then, in order to remove PCT aggregates and free PCT, the mixture was centrifuged (3000 $\mathrm{rpm}$ for $15 \mathrm{~min}$ at $8{ }^{\circ} \mathrm{C}$ ). The supernatant dispersion, of PCTloaded polymersomes in water, was kept, while free PCT and PCT aggregates were precipitated and the precipitate was discarded. The purified product was stored in the fridge (4 $\left.{ }^{\circ} \mathrm{C}\right)$.

The dual DOX/PCT-loaded polymersomes were prepared by a combination of the above processes. In detail, $9 \mathrm{mg}$ of SGQP was dissolved in THF $(0.5 \mathrm{~mL})$, and $1 \mathrm{mg}$ of PCT dissolved in $0.1 \mathrm{~mL}$ of ethanol was added. The PCT/SGQP mixture was allowed to stir for $24 \mathrm{~h}$ in the dark. Then, DOX (1 $\mathrm{mg}$ ) was added in $5.5 \mathrm{~mL}$ of ultrapure $\mathrm{H}_{2} \mathrm{O}$ under gentle agitation for $30 \mathrm{~min}$ in the dark and then the mixture of PCT/ SGQP was added dropwise. The reaction mixture was left under gentle stirring for $30 \mathrm{~min}$. The ratio of DOX/PCT/ SGQP was $1 / 1 / 9$ (in $\mathrm{mg}$ ). The dispersion was rotary vacuumevaporated $\left(35^{\circ} \mathrm{C}\right)$ for $2 \mathrm{~h}$. In order to remove free (not encapsulated) PCT and possible PCT aggregates, the mixture was centrifuged at $\left(3000 \mathrm{rpm}, 15 \mathrm{~min}, 8{ }^{\circ} \mathrm{C}\right)$ and the supernatant was kept. In order to remove free (not encapsulated) DOX, the supernatant was centrifuged (15000 $\mathrm{rpm}, 1 \mathrm{~h}, 8^{\circ} \mathrm{C}$ ). After this centrifugation, the precipitate with the DOX/PCT-loaded polymersomes was resuspended in the initial water volume and the supernatant with the free DOX was discarded. The purified DOX/PCT-loaded polymersomes were stored in the fridge $\left(4^{\circ} \mathrm{C}\right)$.

The quantity of drug loaded in polymersomes was determined by UV-vis spectroscopy, in a UV-1800 Shimadzu spectrophotometer. The DOX-loaded polymersomes were analyzed at $495 \mathrm{~nm}$. The blank polymersomes (with no drug) at $495 \mathrm{~nm}$ had zero absorbance; thus, the DOX signal was clear and not overlapped. The amount of loaded DOX in the polymersomes was calculated based on a calibration curve $\left(R^{2}=0.9989\right)$. The limit of quantification was $0.1 \mu \mathrm{g} / \mathrm{mL}$, and the linear part of the standard curve used for DOX assay was from 0.1 to $50 \mu \mathrm{g} / \mathrm{mL}$.

For the PCT-loaded polymersomes, freeze-dried samples were dissolved in $1 \mathrm{~mL}$ of a $60: 40(\mathrm{v} / \mathrm{v})$ mixture of acetonitrile/water and analyzed using a UV-1800 Shimadzu spectrophotometer at $229 \mathrm{~nm}$. The absorbance of blank polymersomes (with no drug) at $229 \mathrm{~nm}$ was extracted before every measurement. The amount of loaded PCT in the polymersomes was calculated based on a calibration curve $\left(R^{2}\right.$ $=0.9988)$. The limit of quantification was $1 \mu \mathrm{g} / \mathrm{mL}$, and the linear part of the standard curve used for PCT assay was from 1 to $50 \mu \mathrm{g} / \mathrm{mL}$.

In the dual drug-loaded samples, the DOX loading was first determined by UV-vis analysis at $495 \mathrm{~nm}$. Then, the polymersomes were freeze-dried and the PCT loading was determined at $229 \mathrm{~nm}$ as described above. The DOX and PCT 
Table 3. Estimated $\mathrm{IC}_{50}$ Values of Free Drugs and Drug-Loaded Polymersomes and CI Values of the Combined Free Drugs (Free DOX/PCT) and DOX/PCT-Polymersomes at 24 and $48 \mathrm{~h}$ at $50 \%$ of Viability

\begin{tabular}{|c|c|c|c|c|c|c|c|c|}
\hline \multirow[b]{2}{*}{ sample } & \multicolumn{4}{|c|}{$24 \mathrm{~h}$} & \multicolumn{4}{|c|}{$48 \mathrm{~h}$} \\
\hline & $\begin{array}{c}\text { DOX IC } \\
(\mu \mathrm{g} / \mathrm{mL})\end{array}$ & $\begin{array}{l}\text { PCT IC } \\
(\mu \mathrm{g} / \mathrm{mL})\end{array}$ & $\underset{(\mu \mathrm{g} / \mathrm{mL})}{\mathrm{DOX}^{2}}$ & $\mathrm{CI}_{50}$ & $\begin{array}{c}\operatorname{DOX~IC}_{50} \\
(\mu \mathrm{g} / \mathrm{mL})\end{array}$ & $\begin{array}{c}\text { PCT IC }_{50} \\
(\mu \mathrm{g} / \mathrm{mL})\end{array}$ & $\underset{(\mu \mathrm{g} / \mathrm{mL})}{\mathrm{DOX}_{50}}$ & $\mathrm{CI}_{50}$ \\
\hline free DOX & 10.000 & & & & 2.120 & & & \\
\hline free PCT & & 3.180 & & & & 0.140 & & \\
\hline free $\mathrm{DOX} / \mathrm{PCT}$ & & & 14.500 & 0.940 & & & 0.750 & 2.385 \\
\hline DOX-polymersomes & 1.340 & & & & 1.190 & & & \\
\hline PCT-polymersomes & & 14.350 & & & & 0.120 & & \\
\hline DOX/PCT-polymersomes & & & 4.960 & 1.028 & & & 0.610 & 1.790 \\
\hline
\end{tabular}

contents were calculated based on separate calibration curves under the conditions described above.

The loading capacity (LC \%), entrapment efficiency (EE \%), and theoretical (feed) loading ( $\left.L_{\text {th }} \%\right)$ of DOX and PCT in polymersomes were calculated from the equations:

$$
\begin{aligned}
& \mathrm{LC} \%=\frac{W}{W_{\mathrm{C}}+W} \times 100 \\
& \mathrm{EE} \%=\frac{W}{W_{0}} \times 100 \\
& L_{\text {th }} \%=\frac{W_{0}}{W_{\mathrm{C}}+W_{0}} \times 100
\end{aligned}
$$

where $W, W_{\mathrm{C}}$, and $W_{0}$ were the amount $(\mathrm{mg})$ of entrapped drug according to the UV-vis spectroscopy, the amount of polymersomes, and the amount of initially added drug, respectively.

In Vitro Drug Release. The drug release from the polymersomes (DOX, PCT, and DOX/PCT) was evaluated under sink conditions in $\mathrm{PB}$ solutions $(10 \mathrm{mM}, \mathrm{pH}=7.4$ and $\mathrm{pH}=6)$ at 37 and at $25^{\circ} \mathrm{C}$. The ionic strength of the $\mathrm{PB}$ was $154 \mathrm{mM}$, similar to the $149.5 \mathrm{mM}$ of human blood plasma. ${ }^{61}$ The polymersomes were enclosed in dialysis membranes (MWCO of $12 \mathrm{kDa}$ ) and dialyzed against $7 \mathrm{~mL}$ of PB buffer for both $\mathrm{pHs}(\mathrm{pH}=7.4$ and $\mathrm{pH}=6)$ at 37 and at $25{ }^{\circ} \mathrm{C}$ (ambient temperature) in a water bath under gentle agitation. At predetermined time intervals (30 min, 1, 2, 3, 4, 5, and $6 \mathrm{~h}$ ), the release medium was completely removed and replaced with fresh buffer of 37 or $25{ }^{\circ} \mathrm{C}$. The release medium containing DOX was assayed by UV-vis spectroscopy at $495 \mathrm{~nm}$. The amount of released DOX for each release medium $(\mathrm{pH}=7.4$ and $\mathrm{pH}=6)$ was calculated based on separate calibration curves (for $\mathrm{pH}=7.4: R^{2}=0.9990$ and for $\mathrm{pH}=6: R^{2}=$ 0.9981). The limit of quantification for $\mathrm{pH}=7.4$ was $0.1 \mu \mathrm{g} /$ $\mathrm{mL}$ and for $\mathrm{pH}=6$ was $0.05 \mu \mathrm{g} / \mathrm{mL}$. The linear part of the standard curve used for DOX assay for $\mathrm{pH}=7.4$ was from 0.1 to $50 \mu \mathrm{g} / \mathrm{mL}$ and for $\mathrm{pH}=6$ was from 0.05 to $50 \mu \mathrm{g} / \mathrm{mL}$.

The release medium containing PCT for both buffers was treated with $2 \mathrm{~mL}$ of dichloromethane (DCM) in order to extract the drug. Then, the dichloromethane was collected and allowed to evaporate at room temperature, and the solid residue was dissolved in $1 \mathrm{~mL}$ of a $60: 40(\mathrm{v} / \mathrm{v})$ mixture of 3D$\mathrm{H}_{2} \mathrm{O} / \mathrm{MeOH}$. The samples of released PCT were assayed by UV-vis spectroscopy at $229 \mathrm{~nm}$. The PCT content was calculated based on a calibration curve $\left(R^{2}=0.9999\right)$, wherein the limit of quantification was $1 \mu \mathrm{g} / \mathrm{mL}$ and the linear part of the standard curve was from 1 to $50 \mu \mathrm{g} / \mathrm{mL}$.

The release medium containing both DOX and PCT was first assayed by UV-vis spectroscopy at 495 for DOX release, as described above. Then, PCT was extracted from the samples following the above extraction process.

Cellular Studies. The human lung adenocarcinoma epithelial cells A549 (ATCC) were cultured routinely in RPMI-1640 medium supplemented with $10 \%$ (v/v) fetal bovine serum (FBS) and a mixture of antibiotic agents $(1.1 \%$ $\mathrm{v} / \mathrm{v}$ penicillin/streptomycin and $0.15 \% \mathrm{v} / \mathrm{v}$ amphotericin). Cultures were retained at $37{ }^{\circ} \mathrm{C}$ in a humidified atmosphere with $5 \%(\mathrm{v} / \mathrm{v}) \mathrm{CO}_{2}$. The culture medium was changed every $48 \mathrm{~h}$ and cells were harvested with $0.25 \%(\mathrm{v} / \mathrm{v})$ trypsin in phosphate-buffered saline (PBS).

Viability. The cytotoxicity of blank polymersomes, drugloaded (DOX, PCT, and dual DOX/PCT) polymersomes, and free drug (DOX, PCT, and dual DOX/PCT) against the A549 human lung cancer cells was investigated by the MTT assay. ${ }^{62}$ A549 cells were seeded into 24 -well plates at a density of $5 \times$ $10^{4}$ cells/well and allowed to grow and proliferate as a monolayer under standard conditions for $24 \mathrm{~h}$. Then, the supernatant in each well was completely removed and replaced with $500 \mu \mathrm{L}$ of fresh medium comprising different concentrations of free or polymersome-entrapped drug. The concentrations were $1,5,10$, and $15 \mu \mathrm{g} / \mathrm{mL}$ of DOX, PCT, or a physical mixture of DOX and PCT (DOX/PCT ratio approx $1: 1$ by weight). The cytotoxicity of blank (without drug) polymersomes (carrier) was also tested at concentrations corresponding to the concentrations of carrier used in the case of drug-loaded polymersomes in order to generate the drug concentrations mentioned above in the cells incubation medium. The concentrations of blank (without drug) polymersomes were $(8,40,80$, and $120 \mu \mathrm{g} / \mathrm{mL})$ evaluated as control to the drug-loaded polymersomes. After the predetermined time periods ( 24 and $48 \mathrm{~h}$ ) of incubation at $37^{\circ} \mathrm{C}$, the supernatant was removed and the cells were washed with PBS. Then, $200 \mu \mathrm{L}$ of MTT solution (10\% v/v in PBS, $\mathrm{pH}$ 7.4) was added in each well and plates were incubated at $37^{\circ} \mathrm{C}$ for $2 \mathrm{~h}$ in order the formazan crystals to be formed. The medium was completely removed, and $200 \mu \mathrm{L}$ of DMSO was added in each well and incubated at $37^{\circ} \mathrm{C}$ for $15 \mathrm{~min}$ to fully dissolve the formazan crystals. The fluorescence of the crystals (corresponding to cell viability) was determined with a UV spectrophotometer at a wavelength of $490 \mathrm{~nm}$. The experiments were performed in triplicate and repeated three times. To calculate the background fluorescence of the cells, unlabeled cells without addition of any polymersomes or drug were used as a negative control in every measurement. Cytotoxicity was expressed as reduction in cell viability (\%). The $\mathrm{IC}_{50}$ values (Table 3 ) were calculated from the $\%$ cell viability versus concentration data by fitting the dose-effect curves according to a four-parameter logistic model with OriginPro 8 software (Origin Lab Corp, Northampton, MA). 
To discriminate synergistic, additive, or antagonistic cytotoxic effects, ${ }^{63}$ the next equation was used

$$
\mathrm{CI}_{x}=\frac{(\mathrm{D})_{1}}{\left(\mathrm{D}_{x}\right)_{1}}+\frac{(\mathrm{D})_{2}}{\left(\mathrm{D}_{x}\right)_{2}}
$$

where $\left(D_{x}\right)_{1}$ and $\left(D_{x}\right)_{2}$ represent the $\mathrm{IC}_{x}$ value of drug 1 (free DOX) and drug 2 (free PCT) alone, respectively. (D) 1 and (D) ${ }_{2}$ represent the concentration of drug 1 (DOX) and drug 2 (PCT) in the combined delivery (free DOX/PCT or polymersome-entrapped $\mathrm{DOX} / \mathrm{PCT}$ ) at the $\mathrm{IC}_{x}$ value. $\mathrm{CI}>$ 1 indicates antagonism, $\mathrm{CI}=1$ indicates additive effects, and $\mathrm{CI}<1$ indicates synergism.

In Vitro Cellular Uptake. The uptake of FITC-labeled DOX-polymersomes by A549 cells was quantitatively evaluated by flow cytometry. ${ }^{64}$ A549 cells, following the above seeding process, were grown as a monolayer, harvested by trypsinization $(0.25 \% \mathrm{w} / \mathrm{v}$ trypsin), plated in 24 -well plates (density of 5 $\times 10^{4}$ cells per well), and incubated. After $24 \mathrm{~h}$, the supernatant in each well was completely removed and substituted with fresh medium containing FITC-labeled DOX-polymersomes at a DOX concentration of $1 \mu \mathrm{g} / \mathrm{mL}(8$ $\mu \mathrm{g} / \mathrm{mL}$ polymersomes) and incubated for 1,4 , and $24 \mathrm{~h}$. Then, the supernatant was removed; the cells were washed twice with PBS and harvested with $0.25 \%(\mathrm{w} / \mathrm{v})$ trypsin. The fluorescence was measured by flow cytometry using appropriate filters for FITC (excitation $\lambda=495 \mathrm{~nm}$, emission $\lambda=519 \mathrm{~nm}$ ) and DOX (excitation $\lambda=550 \mathrm{~nm}$, emission $\lambda=573 \mathrm{~nm}$ ) in a FACS Calibur, Coulter Epics XL-MCL apparatus. To calculate the background fluorescence of unlabeled cells, cells without any addition of studied particles were used as a negative control in every measurement. Data analysis was performed with the WinMDI cytometry analysis software.

In order to visualize cellular uptake of the FITC-labeled DOX-polymersomes, confocal laser microscopy was used with 4',6-diamidino-2-phenylindole dihydrochloride (DAPI) for the nuclear, DOX for the drug and FITC for the polymersomes staining. ${ }^{65}$ A549 cells were grown on coverslips seeded in 6well plates. Sterilized cover slips (Borosilicate Glass, VWR) were placed in each well followed by the addition of cell suspensions $\left(5 \times 10^{4}\right.$ cells $\left./ \mathrm{mL}\right)$. After $24 \mathrm{~h}$, the cells were incubated with FITC-labeled DOX-polymersomes $(1 \mu \mathrm{g} / \mathrm{mL}$ DOX content) for 1,4 , and $24 \mathrm{~h}$. The cells were washed thrice with PBS and fixed directly onto the glass coverslips using $4 \%$ paraformaldehyde (PFA) dissolved in PBS $(300 \mu \mathrm{L})$ and incubated for $15 \mathrm{~min}$. After washing the cells thrice with PBS, $300 \mathrm{nM}$ DAPI stain solution (nucleic acid staining) was added to cover the cells. The cells were then washed with PBS to remove the stain solution. The slides were drained and mounted with Mowiol 4-88. The obtained specimens were imaged using a Leica SP5 confocal microscope (Germany) using appropriate filters for DAPI (excitation $359 \mathrm{~nm}$, emission $457 \mathrm{~nm}$ ), FITC (excitation $\lambda=495 \mathrm{~nm}$, emission $\lambda=519 \mathrm{~nm}$ ), and DOX (excitation $\lambda=550 \mathrm{~nm}$, emission $\lambda=573 \mathrm{~nm}$ ).

Apoptosis. In brief, phosphatidylserine externalization follows the loss of cellular membrane integrity, which is related with apoptotic or necrotic processes leading to the later stages of cell death. ${ }^{66}$ Annexin V protein (FITC Annexin V, BD Pharmingen) was used to detect the externalization of phosphatidylserine as a marker of apoptosis. A549 cells were seeded into 24 -well plates (density $5 \times 10^{4}$ cells/well) and allowed to grow and proliferate as a monolayer, for $24 \mathrm{~h}$. The supernatant in each well was then replaced with medium containing $40 \mu \mathrm{g} / \mathrm{mL}$ blank, PCT-loaded, DOX-loaded, and DOX/PCT-loaded polymersomes (in the case of the drugloaded polymersomes, the total drug concentration was $5 \mu \mathrm{g} /$ $\mathrm{mL}$ ). After $24 \mathrm{~h}$ incubation, the supernatant in each well was completely removed, the cells were washed with PBS, detached with trypsin $(0.25 \% \mathrm{w} / \mathrm{v}$ trypsin), delivered to FACS tubes, and centrifuged (1600 rpm for $5 \mathrm{~min}$ ); the obtained pellet was washed and resuspended in $1 \mathrm{~mL} 1 \times$ Annexin $\mathrm{V}$ binding buffer. Then, the cells were centrifuged (1600 rpm for $5 \mathrm{~min}$ ), and the obtained pellet was resuspended in $100 \mu \mathrm{L}$ of $1 \times$ Annexin $\mathrm{V}$ binding buffer. The cells were incubated with $5 \mu \mathrm{L}$ of FITC-Annexin V in the dark for $15 \mathrm{~min}$ at room temperature. At the end of the incubation, the cells were washed with $0.5 \mathrm{~mL}$ Annexin $\mathrm{V}$ binding buffer. Cell fluorescence due to Annexin V (\% cell apoptosis) was determined by flow cytometry (excitation $\lambda=495 \mathrm{~nm}$, emission $\lambda=519 \mathrm{~nm}$ ), in a FACS Calibur, Coulter Epics XLMCL apparatus. The background fluorescence of unlabeled cells was determined and used as negative control. Data analysis was performed with the WinMDI cytometry analysis software.

\section{ASSOCIATED CONTENT}

\section{S Supporting Information}

The Supporting Information is available free of charge on the ACS Publications website at DOI: 10.1021/acsomega.8b01437.

Characterization with ${ }^{1} \mathrm{H}$ NMR; methods attempted for the preparation of polymersomes; TEM images of blank and loaded polymersomes; drug delivery profiles up to $48 \mathrm{~h}$; viability of A549 cancer cells following incubation with blank (without drug) SGQP polymersomes; and confocal fluorescence microscopy images of the uptake of FITC-polymersomes and DOX (loaded) by A549 cancer cells (PDF)

\section{AUTHOR INFORMATION}

\section{Corresponding Author}

*E-mail: ct@chemeng.upatras.gr (C.T.).

ORCID $\odot$

Constantinos Tsitsilianis: 0000-0002-7265-9037

Notes

The authors declare no competing financial interest.

\section{ACKNOWLEDGMENTS}

The authors thank Dr Maria Kollia from the Lab of Electron Microscopy and Microanalysis at the University of Patras for the TEM images and the Advanced Light Microscopy Facility of the Medical School at the University of Patras for the Confocal Microscopy images. The authors would like to thank the Advanced Light Microscopy facility of the Department of Physiology, School of Medicine, University of Patras, especially Dr. Argiro Kalogeropoulou and Professor Stavros Taraviras, for their help with the confocal microscopy.

\section{REFERENCES}

(1) Iatridi, Z.; Tsitsilianis, C. Water-soluble stimuli responsive starshaped segmented macromolecules. Polymers 2011, 3, 1911-1933.

(2) Ren, J. M.; McKenzie, T. G.; Fu, Q.; Wong, E. H. H.; Xu, J.; An, Z.; Shanmugam, S.; Davis, T. P.; Boyer, C.; Qiao, G. G. Star Polymers. Chem. Rev. 2016, 116, 6743-6836. 
(3) Aryal, S.; Prabaharan, M.; Pilla, S.; Gong, S. Biodegradable and biocompatible multi-arm star amphiphilic block copolymer as a carrier for hydrophobic drug delivery. Int. J. Biol. Macromol. 2009, 44, 346352.

(4) Ayen, W. Y.; Garkhal, K.; Kumar, N. Doxorubicin-Loaded (PEG)3-PLA Nanopolymersomes: Effect of Solvents and Process Parameters on Formulation Development andIn VitroStudy. Mol. Pharm. 2011, 8, 466-478.

(5) Yang, Y. Q.; Zhao, B.; Li, Z. D.; Lin, W. J.; Zhang, C. Y.; Guo, X. D.; Wang, J. F.; Zhang, L. J. pH-sensitive micelles self-assembled from multi-arm star triblock co-polymers poly( $\varepsilon$-caprolactone)-b-poly(2(diethylamino)ethyl methacrylate)-b-poly(poly(ethylene glycol) methyl ether methacrylate) for controlled anticancer drug delivery. Acta Biomater. 2013, 9, 7679-7690.

(6) Soliman, G. M.; Redon, R.; Sharma, A.; Mejía, D.; Maysinger, D.; Kakkar, A. Miktoarm Star Polymer Based Multifunctional Traceable Nanocarriers for Efficient Delivery of Poorly Water Soluble Pharmacological Agents. Macromol. Biosci. 2014, 14, 1312-1324.

(7) Pramod, P. S.; Shah, R.; Chaphekar, S.; Balasubramanian, N.; Jayakannan, M. Polysaccharide nano-vesicular multidrug carriers for synergistic killing of cancer cells. Nanoscale 2014, 6, 11841-11855.

(8) Zhou, P.; Liu, Y.-Y.; Niu, L.-Y.; Zhu, J. Self-assemblies of the sixarmed star triblock $\mathrm{ABC}$ copolymer: $\mathrm{pH}$-tunable morphologies and drug release. Polym. Chem. 2015, 6, 2934-2944.

(9) Wu, W.; Wang, W.; Li, J. Star polymers: Advances in biomedical applications. Prog. Polym. Sci. 2015, 46, 55-85.

(10) Triftaridou, A. I.; Vamvakaki, M.; Patrickios, C. S.; Stavrouli, N.; Tsitsilianis, C. Synthesis of Amphiphilic (ABC)nMultiarm Star Triblock Terpolymers. Macromolecules 2005, 38, 1021-1024.

(11) Stavrouli, N.; Triftaridou, A. I.; Patrickios, C. S.; Tsitsilianis, C. Multi-Compartment Unimolecular Micelles from (ABC)n Multi-Arm Star Triblock Terpolymers. Macromol. Rapid Commun. 2007, 28, 560-566.

(12) Iatridi, Z.; Roiter, Y.; Stavrouli, N.; Minko, S.; Tsitsilianis, C. Phase behavior and self-assembly of PSn(P2VP-b-PAA)n multiarmed multisegmented star terpolymers with ampholytic arms. Polym. Chem. 2011, 2, 2037-2044.

(13) Iatridi, Z.; Tsitsilianis, C. $\mathrm{pH}$ responsive self assemblies from an An-core-(B-b-C)n heteroarm star block terpolymer bearing oppositely charged segments. Chem. Commun. 2011, 47, 5560-5562.

(14) Choi, I.; Malak, S. T.; Xu, W.; Heller, W. T.; Tsitsilianis, C.; Tsukruk, V. V. Multicompartmental microcapsules from Star copolymer micelles. Macromolecules 2013, 46, 1425-1436.

(15) Kim, B.-S.; Park, S. W.; Hammond, P. T. Hydrogen-Bonding Layer-by-Layer-Assembled Biodegradable Polymeric Micelles as Drug Delivery Vehicles from Surfaces. ACS Nano 2008, 2, 386-392.

(16) Chandrawati, R.; van Koeverden, M. P.; Lomas, H.; Caruso, F. Multicompartment Particle Assemblies for Bioinspired Encapsulated Reactions. J. Phys. Chem. Lett. 2011, 2, 2639-2649.

(17) Xu, W.; Ledin, P. A.; Plamper, F. A.; Synatschke, C. V.; Müller, A. H. E.; Tsukruk, V. V. Multiresponsive Microcapsules Based on Multilayer Assembly of Star Polyelectrolytes. Macromolecules 2014, 47, 7858-7868.

(18) Erwin, A. J.; Korolovych, V. F.; Iatridi, Z.; Tsitsilianis, C.; Ankner, J. F.; Tsukruk, V. V. Tunable Compartmentalized Morphologies of Multilayered Dual Responsive Star Block Polyampholytes. Macromolecules 2018, 51, 4800-4812.

(19) Antonietti, M.; Förster, S. Vesicles and Liposomes: A SelfAssembly Principle Beyond Lipids. Adv. Mater. 2003, 15, 1323-1333.

(20) Ahmed, F.; Photos, P. J.; Discher, D. E. Polymersomes as Viral Capsid Mimics. Drug Dev. Res. 2006, 67, 4-14.

(21) Ahmed, F.; Pakunlu, R. I.; Brannan, A.; Bates, F.; Minko, T.; Discher, D. E. Biodegradable polymersomes loaded with both paclitaxel and doxorubicin permeate and shrink tumors, inducing apoptosis in proportion to accumulated drug. J. Controlled Release 2006, 116, 150-158.

(22) Tanner, P.; Baumann, P.; Enea, R.; Onaca, O.; Palivan, C.; Meier, W. Polymeric Vesicles: From Drug Carriers to Nanoreactors and Artificial Organelles. Acc. Chem. Res. 2011, 44, 1039-1049.
(23) Jain, J. P.; Ayen, W. Y.; Kumar, N. Self Assembling Polymers as Polymersomes for Drug Delivery. Curr. Pharm. Des. 2011, 17, 65-79.

(24) Lee, J. S.; Feijen, J. Polymersomes for drug delivery: Design, formation and characterization. J. Controlled Release 2012, 161, 473483.

(25) Lomas, H.; Canton, I.; MacNeil, S.; Du, J.; Armes, S. P.; Ryan, A. J.; Lewis, A. L.; Battaglia, G. Biomimetic pH Sensitive Polymersomes for Efficient DNA Encapsulation and Delivery. Adv. Mater. 2007, 19, 4238-4243.

(26) Lomas, H.; Du, J.; Canton, I.; Madsen, J.; Warren, N.; Armes, S. P.; Lewis, A. L.; Battaglia, G. Efficient Encapsulation of Plasmid DNA in pH-Sensitive PMPC-PDPA Polymersomes: Study of the Effect of PDPA Block Length on Copolymer-DNA Binding Affinity. Macromol. Biosci. 2010, 10, 513-530.

(27) Zheng, C.; Yao, X.; Qiu, L. Novel Polymeric Vesicles with pHInduced Deformation Character for Advanced Drug Delivery. Macromol. Biosci. 2011, 11, 338-343.

(28) Du, J.; Fan, L.; Liu, Q. pH-Sensitive Block Copolymer Vesicles with Variable Trigger Points for Drug Delivery. Macromolecules 2012, $45,8275-8283$.

(29) Jeong, I. K.; Gao, G. H.; Li, Y.; Kang, S. W.; Lee, D. S. A Biodegradable Polymersome with $\mathrm{pH}$-Tuning On-Off Membrane Based on Poly ( $\beta$-amino ester $)$ for Drug Delivery. Macromol. Biosci. 2013, 13, 946-953.

(30) Popescu, M.-T.; Tsitsilianis, C. Controlled Delivery of Functionalized Gold Nanoparticles by pH-Sensitive Polymersomes. ACS Macro Lett. 2013, 2, 222-225.

(31) Popescu, M.-T.; Korogiannaki, M.; Marikou, K.; Tsitsilianis, C. CBABC terpolymer-based nanostructured vesicles with tunable membrane permeability as potential hydrophilic drug nanocarriers. Polymer 2014, 55, 2943-2951.

(32) Wang, L.; Liu, G.; Wang, X.; Hu, J.; Zhang, G.; Liu, S. AcidDisintegratable Polymersomes of $\mathrm{pH}$-Responsive Amphiphilic Diblock Copolymers for Intracellular Drug Delivery. Macromolecules 2015, 48, 7262-7272.

(33) Qin, S.; Geng, Y.; Discher, D. E.; Yang, S. TemperatureControlled Assembly and Release from Polymer Vesicles of Poly(ethylene oxide)-block-poly(N-isopropylacrylamide). $A d v$. Mater. 2006, 18, 2905-2909.

(34) Liu, F.; Kozlovskaya, V.; Medipelli, S.; Xue, B.; Ahmad, F.; Saeed, M.; Cropek, D.; Kharlampieva, E. Temperature-Sensitive Polymersomes for Controlled Delivery of Anticancer Drugs. Chem. Mater. 2015, 27, 7945-7956.

(35) Li, J.; Dirisala, A.; Ge, Z.; Wang, Y.; Yin, W.; Ke, W.; Toh, K.; Xie, J.; Matsumoto, Y.; Anraku, Y.; Osada, K.; Kataoka, K. Therapeutic Vesicular Nanoreactors with Tumor-Specific Activation and Self-Destruction for Synergistic Tumor Ablation. Angew. Chem., Int. Ed. 2017, 56, 14025-14030.

(36) Li, J.; Li, Y.; Wang, Y.; Ke, W.; Chen, W.; Wang, W.; Ge, Z. Polymer Prodrug-Based Nanoreactors Activated by Tumor Acidity for Orchestrated Oxidation/Chemotherapy. Nano Lett. 2017, 17, 69836990.

(37) Iatridi, Z.; Lencina, M. M. S.; Tsitsilianis, C. PNIPAM-based heteroarm star-graft quarterpolymers: synthesis, characterization and pH-dependent thermoresponsiveness in aqueous media. Polym. Chem. 2015, 6, 3942-3955.

(38) Xu, W.; Ledin, P. A.; Iatridi, Z.; Tsitsilianis, C.; Tsukruk, V. V. Multicompartmental Microcapsules with Orthogonal Programmable Two-Way Sequencing of Hydrophobic and Hydrophilic Cargo Release. Angew. Chem., Int. Ed. 2016, 55, 4908-4913.

(39) Maeda, H. The enhanced permeability and retention (EPR) effect in tumor vasculature: the key role of tumor-selective macromolecular drug targeting. Adv. Enzyme Regul. 2001, 41, 189207.

(40) Prabhakar, U.; Maeda, H.; Jain, R. K.; Sevick-Muraca, E. M.; Zamboni, W.; Farokhzad, O. C.; Barry, S. T.; Gabizon, A.; Grodzinski, P.; Blakey, D. C. Challenges and Key Considerations of the Enhanced Permeability and Retention Effect for Nanomedicine Drug Delivery in Oncology. Cancer Res. 2013, 73, 2412-2417. 
(41) Wang, H.; Zhao, Y.; Wu, Y.; Hu, Y.-1.; Nan, K.; Nie, G.; Chen, $\mathrm{H}$. Enhanced anti-tumor efficacy by co-delivery of doxorubicin and paclitaxel with amphiphilic methoxy PEG-PLGA copolymer nanoparticles. Biomaterials 2011, 32, 8281-8290.

(42) Lv, S.; Tang, Z.; Li, M.; Lin, J.; Song, W.; Liu, H.; Huang, Y.; Zhang, Y.; Chen, X. Co-delivery of doxorubicin and paclitaxel by PEG-polypeptide nanovehicle for the treatment of non-small cell lung cancer. Biomaterials 2014, 35, 6118-6129.

(43) Kitaeva, M. V.; Melik-Nubarov, N. S.; Menger, F. M.; Yaroslavov, A. A. Doxorubicin-Poly(acrylic acid) Complexes: Interaction with Liposomes. Langmuir 2004, 20, 6575-6579.

(44) von Minckwitz, G.; Raab, G.; Caputo, A.; Schütte, M.; Hilfrich, J.; Blohmer, J. U.; Gerber, B.; Costa, S. D.; Merkle, E.; Eidtmann, H.; Lampe, D.; Jackisch, C.; du Bois, A.; Kaufmann, M. Doxorubicin with cyclophosphamide followed by docetaxel every 21 days compared with doxorubicin and docetaxel every 14 days as preoperative treatment in operable breast cancer: the GEPARDUO study of the German Breast Group. J. Clin. Oncol. 2005, 23, 2676-2685.

(45) Moulder, S. L.; Symmans, W. F.; Booser, D. J.; Madden, T. L.; Lipsanen, C.; Yuan, L.; Brewster, A. M.; Cristofanilli, M.; Hunt, K. K.; Buchholz, T. A.; Zwiebel, J.; Valero, V.; Hortobagyi, G. N.; Esteva, F. J. Phase I/II study of G3139 (Bcl-2 antisense oligonucleotide) in combination with doxorubicin and docetaxel in breast cancer. Clin. Cancer Res. 2008, 14, 7909-7916.

(46) Han, M.; Lv, Q.; Tang, X.-J.; Hu, Y.-L.; Xu, D.-H.; Li, F.-Z.; Liang, W.-Q.; Gao, J.-Q. Overcoming drug resistance of MCF-7/ADR cells by altering intracellular distribution of doxorubicin via MVP knockdown with a novel siRNA polyamidoamine-hyaluronic acid complex. J. Controlled Release 2012, 163, 136-144.

(47) Duan, X.; Xiao, J.; Yin, Q.; Zhang, Z.; Yu, H.; Mao, S.; Li, Y. Smart $\mathrm{pH}$-sensitive and temporal-controlled polymeric micelles for effective combination therapy of doxorubicin and disulfiram. ACS Nano 2013, 7, 5858-5869.

(48) Hu, C.-M. J.; Aryal, S.; Zhang, L. Nanoparticle-assisted combination therapies for effective cancer treatment. Ther. Delivery 2010, 1, 323-334.

(49) Zhao, Y.; Alakhova, D. Y.; Kabanov, A. V. Can nanomedicines kill cancer stem cells? Adv. Drug Delivery Rev. 2013, 65, 1763-1783.

(50) Marsden, H. R.; Gabrielli, L.; Kros, A. Rapid preparation of polymersomes by a water addition/solvent evaporation method. Polym. Chem. 2010, 1, 1512-1518.

(51) Manocha, B.; Margaritis, A. Controlled Release of Doxorubicin from Doxorubicin $/ \gamma$-Polyglutamic Acid Ionic Complex. J. Nanomater. 2010, 2010, 1-9.

(52) Chen, Y.; Zhang, W.; Huang, Y.; Gao, F.; Sha, X.; Fang, X. Pluronic-based functional polymeric mixed micelles for co-delivery of doxorubicin and paclitaxel to multidrug resistant tumor. Int. J. Pharm. 2015, 488, 44-58.

(53) Sethuraman, V. A.; Bae, Y. H. TAT peptide-based micelle system for potential active targeting of anti-cancer agents to acidic solid tumors. J. Controlled Release 2007, 118, 216-224.

(54) Kato, Y.; Ozawa, S.; Miyamoto, C.; Maehata, Y.; Suzuki, A.; Maeda, T.; Baba, Y. Acidic extracellular microenvironment and cancer. Cancer Cell Int. 2013, 13, 89.

(55) Xu, S.; Wang, W.; Li, X.; Liu, J.; Dong, A.; Deng, L. Sustained release of PTX-incorporated nanoparticles synergized by burst release of DOX.HCl from thermosensitive modified PEG/PCL hydrogel to improve anti-tumor efficiency. Eur. J. Pharm. Sci. 2014, 62, 267-273. (56) Lee, W. L.; Guo, W. M.; Ho, V. H. B.; Saha, A.; Chong, H. C.; Tan, N. S.; Tan, E. Y.; Loo, S. C. J. Delivery of doxorubicin and paclitaxel from double-layered microparticles: The effects of layer thickness and dual-drug vs. single-drug loading. Acta Biomater. 2015, $27,53-65$.

(57) Nasser, M. W.; Datta, J.; Nuovo, G.; Kutay, H.; Motiwala, T.; Majumder, S.; Wang, B.; Suster, S.; Jacob, S. T.; Ghoshal, K. Downregulation of Micro-RNA-1 (miR-1) in Lung Cancer. J. Biol. Chem. 2008, 283, 33394-33405.
(58) Zhang, X.-Y.; Zhang, Y.-D. Enhanced antiproliferative and apoptosis effect of paclitaxel-loaded polymeric micelles against nonsmall cell lung cancers. Tumor Biol. 2015, 36, 4949-4959.

(59) Hahn, S. M.; Liebmann, J. E.; Cook, J.; Fisher, J.; Mitchell, J. B.; Kaufman, D.; Goldspiel, B.; Venzon, D. Taxol in Combination with Doxorubicin or Etoposide Possible Antagonism In Vitro. Cancer 1993, 72, 2705-2711.

(60) Xu, W.; Ledin, P. A.; Iatridi, Z.; Tsitsilianis, C.; Tsukruk, V. V. Multiresponsive Star-Graft Quarterpolymer Monolayers. Macromolecules 2015, 48, 3344-3353.

(61) Tas, A. C. Use of biomineralization media in biomimetic synthesis of hard tissue substitutes. In Advances in Bioceramics and Biotechnologies II; McKittrick, J. M., Narayan, R., Eds.; Wiley: USA, 2014; p 92.

(62) Mosmann, T. Rapid colorimetric assay for cellular growth and survival: Application to proliferation and cytotoxicity assays. J. Immunol. Methods 1983, 65, 55-63.

(63) Chou, T.-C. Theoretical basis, experimental design, and computerized simulation of synergism and antagonism in drug combination studies. Pharmacol. Rev. 2006, 58, 621-681.

(64) Yuan, H.; Miao, J.; Du, Y.; You, J.; Hu, F.; Zeng, S. Cellular uptake of solid lipid nanoparticles and cytotoxicity of encapsulated paclitaxel in A549 cancer cells. Int. J. Pharm. 2008, 348, 137-145.

(65) Koutsiouki, K.; Angelopoulou, A.; Ioannou, E.; Voulgari, E.; Sergides, A.; Magoulas, G. E.; Bakandritsos, A.; Avgoustakis, K. TAT Peptide-Conjugated Magnetic PLA-PEG Nanocapsules for the Targeted Delivery of Paclitaxel: In Vitro and Cell Studies. AAPS PharmSciTech 2017, 18, 769-781.

(66) Foldbjerg, R.; Dang, D. A.; Autrup, H. Cytotoxicity and genotoxicity of silver nanoparticles in the human lung cancer cell line, A549. Arch. Toxicol. 2011, 85, 743-750. 